\title{
A REVIEW OF FLOW BOILING IN MINI AND MICROCHANNEL FOR ENHANCED GEOMETRIES
}

\author{
Alican Çebi ${ }^{1}$, Ali Celen², Aydın Hacı Donmez ${ }^{3}$, Yakup Karakoyun ${ }^{3}$, Pınar Celen ${ }^{1,4}$, Mehmet Salih \\ Cellek ${ }^{1}$, Ahmet Selim Dalkiliç ${ }^{1, *}$, Tolga Taner ${ }^{5,}$, , Somchai Wongwises ${ }^{6}$
}

\begin{abstract}
Flow boiling researches in enhanced geometries practiced recently have been summarized in this review. Classical approximations in macroscale flows have not applied to the flows with small hydraulic diameters, so, this subject has been paid attention by the researchers. Application areas of these structures are increasing continuously due to cooling need in small confined spaces. The related studies have been reviewed in a chronological manner and their parameters have been given in a table in order for the researchers to observe the scientific duration regarding the progresses on this subject. Almost all papers on this subject have been produced after 2000 , therefore, this subject is considered as an actual one to improve and worth to study in the literature. This study can not only be evaluated as the beginning argument for the researchers involved in flow boiling process in mini and microchannel, but it also consists of new works on the investigated subject.
\end{abstract}

\section{Keywords: Refrigeration, Alternative Refrigerants, Boiling, Evaporator, Mini Channel, Microchannel}

\section{INTRODUCTION}

Recent developments in various areas raised the need for smaller heat transfer devices with high heat fluxes. Although mini and micro heat and mass transfer structures in nature are widely common and known for a very long time, industrial and academic interest towards the subject is relatively new compared to conventional heat transfer geometries. While the transition to mini or micro structure threshold is studied extensively by many researchers, channel dimensions smaller than $3 \mathrm{~mm}$ and $200 \mu \mathrm{m}$ are named as mini and microchannel, respectively (see in Appendix Tables A1).

Some application areas, such as high performance CPU (Central Processing Unit) processors, have high heat fluxes to dissipate in small length scales. Due to fast increasing in computing capacity, heat fluxes in those devices even approached such scales that require boiling flow to remove heat without damaging equipment. For a circular tube, it is well known that the ratio of surface area to volume increases as the diameter of the tube decreases. This result alone, make mini and microstructures attractive for the applications mentioned previously. Due to small-scales however, classic theories applied to the conventional scale channels are not applicable to mini/micro structures. To the authors' knowledge, a satisfying model that is capable of solving the multiphase phenomenon in these structures is not successfully developed to date. The main reasons behind this are the merge of complex nature of multiphase flows and lack of complete understanding of the driving mechanisms in smallscale channels. Instrumentation and measurement are also major difficulties encountered in experimental studies. At these scale, even uncertainties may be a significant contributor to the diversity of the data experienced throughout different studies (see in Appendix Tables A1 and Tables A2).

However, in recent years, researchers from heat transfer community made considerable amount of studies on small-scale channels. One may find information about nearly all modes of heat transfer in mini/microchannel in the literature. One may also find other reviews on the subject namely Thome [1], Cheng and Mewes [2], Baldassari and Marengo [3], Tibiriçá and Ribatski [4], Kandlikar [5], Lin et al. [6] and Wu and Sundén [7]. Some of these reviews investigated specific modes of heat transfer while some contain multiple or all modes. This review

This paper was recommended for publication in revised form by Regional Editor Ahmed Kadhim Hussein

${ }^{1}$ Heat and Thermodynamics Division, Department of Mechanical Engineering, Faculty of Mechanical Engineering, Yildiz Technical University (YTU), Yildiz, Besiktas, Istanbul 34349, Turkey

${ }^{2}$ Thermodynamics Division, Department of Mechanical Engineering, Faculty of Engineering, Erzincan University, Erzincan 24100, Turkey

${ }^{3}$ Hydromechanics and Hydraulic Machines Division, Department of Mechanical Engineering, Faculty of Mechanical Engineering, Yildiz Technical University (YTU), Yildiz, Besiktas, Istanbul 34349, Turkey

${ }^{4}$ Energy Division, Department of Mechanical Engineering, Faculty of Engineering, Gümüşhane University, Gümüşhane 29100, Turkey

${ }^{5}$ Department of Motor Vehicles and Transportation Technology, Vocational School of Technical Sciences, Aksaray University, 68100 Aksaray, Turkey

${ }^{6}$ Fluid Mechanics, Thermal Engineering and Multiphase Flow Research Lab. (FUTURE),

Department of Mechanical Engineering, Faculty of Engineering, King Mongkut's University of Technology Thonburi (KMUTT), Bangmod, Bangkok 10140, Thailand

*E-mail address: dalkilic@ytu.edu.tr \& tolgataner@aksaray.edu.tr

Manuscript Received 7 August 2017, Accepted 20 September 2017 
however, focused on the boiling in mini and microchannel only. Some of these review papers are summarized as shown below. Kim and Mudawar [8] carried out a wide review of studies regarding pressure drop in mini and microchannel structures to assemble a large database of experiments and demonstrate the performance of individual pressure drop models. In their study, authors give comprehensive background information about flow instabilities and pressure drop models in two-phase mini/micro flows. Total number of 7115 experimental data points, which grouped under the titles of adiabatic/condensation and boiling, are gathered through investigated studies. A universal model developed by the same authors showed good performance of prediction regarding with the experimental data assembled from different studies. Corresponding model is capable of predicting the frictional data with wide range of working conditions and fluid types. Authors concluded that the future efforts in mini/micro channels should be directed to the theoretical and numerical computations of the two-phase flows although these subjects will demand more complex models due to the nature of the size effects of the channels. Salman et al. [9] presented a review about fluid flow and heat transfer characteristics of microchannel, micro tubes and nanofluids. They noted that the studies with nano fluid flowing in microchannel and micro tube must be conducted for better heat transfer results instead of conventional fluids. Moreover, they concluded that microchannel having triangular channel had the best thermal efficiency compared to other channel types such as trapezoidal and rectangular. They also mentioned about difficulties of using nanofluids in microchannel and microtubes as higher pressure drop (pumping power), homogenous distribution of nanoparticles, high nanofluids price, decreased specific heat and increased viscosity.

Classification of the studies has been prepared based on the chronological publication dates of individual papers. This approach was preferred in order to reveal the trends throughout time and to identify the possible new directions for the researchers in the subject.

\section{BOILING HEAT TRANSFER and PRESSURE DROP INSIDE MINICHANNELS AND MICROCHANNEL}

Many studies about fundamental issues and experiments have been performed to determine the characteristics of convective boiling flow in mini and microchannel. According to the previous studies in the literature, boiling phenomena in these channels has different characteristics regarding in boiling transition, flow regimes and heat transfer features.

The local fluid pressure is considered as one of the most significant parameters characterizing the twophase flow in mini and microchannel. There are not enough empirical correlations for two-phase flows' heat transfer coefficients and friction factors due to the generalization problem. In order to determine the thermal characteristics of the two-phase flow in mini and microchannel, an appropriate usage of the models and correlations regarding with the heat transfer coefficients and friction factors are necessary due to the fact that an important alteration in properties is occurred during two-phase flows in channels. The determination of pressure influences is crucial in designing two-phase mini and microchannel devices, because it affects the energy consumption of pumping power of the device. On the other hand, the success of determination is usually not very notable and the error bands of $30 \%$ is classic in fact for the most progressive theoretical models. There are two popular models named homogeneous and separated flow models in open sources on this subject.

The total pressure drop can be considered as the sum of frictional, acceleration, and gravitational terms for the two-phase flows in straight channels with unchanging cross sectional areas. The gravitational term is usually minor in comparison to the two other terms and can be omitted in mini and microchannel. Therefore, the pressure drop of two-phase flow in horizontal mini microchannel may be considered as a calculation of frictional and acceleration terms.

\section{RESULT and DISCUSSION}

Information regarding the operating conditions and flow geometries for investigated papers, selected models for predicting heat transfer coefficient and critical heat flux are presented in Table A1 [10-15, 17-22, 2531, 33-35, 44-52, 59, 61-66, 68, 70-74, 76, 78-82, 85-89, 91-97, 100-109], Table A2 [15, 16, 20, 24, 31, 34, 37, 44, 45, 47, 56, 70, 86, 109] and Table A3 [38, 41, 52, 83, 87, 133]. These tables are in Appendix section. Studies on the flow boiling in mini and microchannel are summarized considering their specific topics, experimental parameters, findings and new aspects in the following paragraphs. 


\section{Minichannel Geometry}

The works in minichannels on this subject are summarized from literature. Kew and Cornwell [10] investigated pressure drop and boiling heat transfer coefficient for compact two-phase heat exchangers whose tube's length $500 \mathrm{~mm}$ and diameters 1.39-3.69 $\mathrm{mm}$. The refrigerant used in the test was R141b. The correlations, used to find heat transfer coefficients, assumed well for largest tube but work badly for smaller tubes. The purpose of the study was to select suitable design correlation to find heat transfer coefficient for new types advanced compact heat exchangers. The authors realized that conventional in tube flow boiling might be applied for tubes, which have confinement number of order of 0.3 and above. In addition, they recognized that a film flow model might be used for evaluation of heat transfer coefficient in narrow channel in the absence of dry-out, low heat fluxes and qualities. Lee and Lee [11] have proposed a correlation to determine heat transfer coefficient due to boiling flows through horizontal rectangular channels as obtained from the experimental setup, whose gap changes from $0.4 \mathrm{~mm}$ to $2.0 \mathrm{~mm}$. They used Joule heating method to supply heat for test section and their maximum measurement uncertainty for heat transfer coefficient was $18.1 \%$. In addition, channel width was fixed as $20 \mathrm{~mm}$. They used R113 as a test refrigerant. Heat flux, whose value was fixed at $15 \mathrm{~kW} / \mathrm{m}^{2}$ as constant, was uniformly applied to channel walls. The mass flux was arranged from 50 to $200 \mathrm{~kg} \mathrm{~m}^{-2} \mathrm{~s}^{-1}$. Apart from heat transfer coefficient, they examined pressure drop according to Lochart-Martinelli correlation. The frictional pressure drop was determined to be with an accuracy of $20 \%$. According to experimental data, while for the higher flow rate $\left(\operatorname{Re}_{\mathrm{LF}}>200\right)$ deviation was determined as $10.7 \%$ due to the Kandlikar's flow boiling correlation [5], for the lower flow rate ( $\operatorname{ReLF} \leq 200)$ deviation changed $\pm 20 \%$ according to the two-phase frictional correlation proposed by Lee and Lee [11]. Kandlikar and Steinke [12] modified a flow boiling correlation for large-diameter tubes. They made it for flow boiling in minichannels by using the laminar single-phase correlation for the heat transfer coefficient for all liquid flow. They compared the trends in quality and heat transfer in the laminar region. Perfect results are acquired between estimated values and experimental data. Kandlikar and Balasubramanian [13] extended the boiling correlations for wider channels, constituted by Kandlikar [5], to minichannels by using the laminar singlephase heat transfer coefficient because, the flow in those narrow tubes with low flow rates are mostly laminar. These correlations are valid for all liquid types. The flows through the channels with diameter larger than $3 \mathrm{~mm}$ must be examined cautiously because the flow can revolve from laminar to turbulent immediately. The heat transfer characteristics are examined in laminar zones of the minichannels and microchannel. The test results showed a brilliant agreement with the empirical correlations. Agostini and Bontemps [14] experimentally studied the ascendant forced flow boiling in minichannels. The working fluid was refrigerant R134a. 11 parallel rectangular channels with hydraulic diameter of $2.01 \mathrm{~mm}$ which were composed the flat aluminium tube was used in experiments. The range of mass flux was between 90 and $295 \mathrm{~kg} \mathrm{~m}^{-2} \mathrm{~s}^{-1}$ and the range of heat flux was between 6.0 and $31.6 \mathrm{~kW} \mathrm{~m}^{-2}$. The tested pressures were 405 and $608 \mathrm{kPa}$. The variation of inlet subcooling was 1 to $17 \mathrm{~K}$. According to the tests' results, when compare with the heat transfer of the previous research; the heat transfer was greater than results from conventional tubes. Yun et al. [15] conducted experiments to measure and analyse the flow boiling heat transfer coefficients in mini tubes with inner diameters of 2.0 and $0.89 \mathrm{~mm}$. The working fluid was $\mathrm{CO}_{2}$ and the operating parameters were high mass fluxes from 500 to $3570 \mathrm{~kg} \mathrm{~m}^{-2} \mathrm{~s}^{-1}$, heat fluxes from 7 to $18 \mathrm{~kW} \mathrm{~m}^{-2}$ and saturation temperatures of 0.5 to $10^{\circ} \mathrm{C}$. The heat transfer coefficients, which were measured before dry out process, were in the range of $10000-20000 \mathrm{~W} \mathrm{~m}^{-2} \mathrm{~K}^{-1}$. According to the experiments, heat flux at entire mass flux cases fiercely affected the heat transfer coefficients before critical vapour quality. This condition considerably occurred when the superficial liquid Weber number was less than 100. Through partial dried liquid film and rate of liquid droplets in vapour core, the heat transfer characteristics after critical vapour quality were expressed. A correlation, which refers to boiling heat transfer before critical vapour quality, was formed. Performance of this correlation was presented. Jokar et al. [16] studied on the two-phase heat transfer. They examined the parameters that affect this type of heat transfer within the mini channel plate of heat exchangers. The other aim of this study was to make useful the dimensional analysis technique for correlations. To carry out this, in the experiments three mini channel brazed-type plate heat exchangers were used and examined. The working fluids were refrigerant R134a and 50\% glycol-water which in counter-flow manner. In the test setup, the heat exchangers were used like an automotive refrigeration system. Due to the results of this experimental study, it was seen that the correlations and two-phase theories, which were used for conventional macro channel heat exchangers may not, used for minichannels. Choi et al. [17] studied convective boiling heat transfer in horizontal minichannels using R22, R134a, and $\mathrm{CO}_{2}$. They obtained local heat transfer coefficient as 10 to $40 \mathrm{~kW} \mathrm{~m}^{-2}$, mass fluxes range 
200 to $600 \mathrm{~kg} \mathrm{~m}^{-2} \mathrm{~s}^{-1}$, a saturation temperature of $10^{\circ} \mathrm{C}$ and quality up to 1.0 . Stainless-steel tubes are used as test material, which have $2000 \mathrm{~mm}$ length, 1.5 , and $3.0 \mathrm{~mm}$ inner diameters. The materials heated directly by applying electric current. Nucleate boiling heat transfer take into account as main contributor especially for low vapour quality region. Average of heat transfer coefficients with their alterations with vapour quality and mass flux were presented for R22, R134a, and $\mathrm{CO}_{2}$. Also in minichannels, researchers observed laminar flows. Researchers present a new boiling transfer coefficient as the mean deviation of $11.21 \%$ conditions on minichannels. Researchers used R22, R134a, and $\mathrm{CO}_{2}$ refrigerants in minichannels and they observed that vapour quality and mass flux have significant importance on the heat transfer coefficient at the low quality region. At the moderate quality region, they observed that the coefficient of heat transfer increase with increase of mass flux and increase of vapour quality. At the high quality region a decrease at the heat transfer coefficient occurs at a lower quality for a higher mass flux condition. It is clear to say that a strong dependence of heat transfer coefficient on the heat flux appears for low quality region. Researchers presented mean heat transfer coefficients for R22, $\mathrm{R} 134 \mathrm{a}$, and $\mathrm{CO}_{2}$ and detailed some other results in the study. Choi et al. [18] studied experimentally two-phase pressure drop of R410A in horizontal smooth minichannels with the inner diameter of 1.5 and $3 \mathrm{~mm}$. They showed the effects of mass flux and the tube diameter on pressure drop in presented study. Moreover, they compared the experimental results against 15 twophase pressure drop previous correlations. Finally, they developed a new correlation based on the LockhartMartinelli method to predict the pressure drop with 4\% mean deviation. Pamitran et al. [19] conducted experiments to determine pressure drop due to vaporization of natural refrigerant $\mathrm{CO}_{2}$ in a horizontal smooth minichannels, which was made of stainless tubes. For experiments, inner diameters of 1.5 and $3.0 \mathrm{~mm}$ were used, as well as, the lengths of test section was $2000 \mathrm{~mm}$ and $3000 \mathrm{~mm}$. Inlet saturation temperatures were adjusted $-10,0$ and $10^{\circ} \mathrm{C}$ at tests. Mass fluxes varied from 200 to $600 \mathrm{~kg} \mathrm{~m}^{-2} \mathrm{~s}^{-1}$, when heat fluxes varied from 10 to $30 \mathrm{~kW} \mathrm{~m}^{-2}$. They compared experimental results with 13 two-phase prediction methods for pressure drop from the literature. In addition, they developed a correlation, which was based on the Lockhart-Martinelli. Bertsch et al. [20] studied on a composite heat transfer correlation, which included nucleate boiling and convective heat transfer terms additionally modified to account for the effects of small channel size, validated against to 3899 data points for minichannels and microchannel from 14 studies in the literature. The new correlation demonstrated very good agreement with the magnitudes and trends of variation of the heat transfer coefficient from most data sets with a mean absolute error of $28 \%$. The correlation was particularly established for vertical and horizontal flow, single and multiple parallel channel arrangements, both wetting and non-wetting fluids. Moreover, it included the effects of heat flux, mass flux, and vapour quality and bubble confinement. In the experimental study of Choi et al. [21] two phase flow boiling pressure drop and heat transfer were performed in horizontal minichannels with an alternative refrigerant namely propane. In this study the effect of some parameters namely mass flux, heat flux, inner tube diameter and saturation temperature on the pressure drop and heat transfer coefficient were investigated experimentally then the results were compared against several existing prediction methods. Finally, a new correlation, which was able to predict the pressure drop and heat transfer, developed for heat exchanger with minichannels design. Koşar [22] developed a basic model in order to predict critical heat flux (CHF) conditions in minichannels and microchannel. For this purpose, the author collected experimental data from previous studies, which had different operating conditions; such as different sizes $\left(0.223 \mathrm{~mm}<\mathrm{d}_{\mathrm{h}}<3.1 \mathrm{~mm}\right)$ and shapes (circular and rectangular). The other conditions are under various operating conditions such as mass velocities $\left(50 \mathrm{~kg} \mathrm{~m}^{-2} \mathrm{~s}^{-1}<\mathrm{G}<1650 \mathrm{~kg} \mathrm{~m}^{-2} \mathrm{~s}-1\right.$, system pressures (101 kPa $<\mathrm{P}<888 \mathrm{kPa}$ ), and working fluids (Water, R123, R113, R134a, and R245fa). The author declared that the developed model performance was consistently better for thin wall/substrate minichannels and microchannel configurations having effective protection from boiling instabilities. It was seen that this model exhibited an effective tool for predicting the CHF in minichannels and microchannel of various geometrical shapes under a broad range of working conditions. Sun and Mishima [23] emphasized the importance of pressure drop in two-phase channel flows in the projects of heat exchangers. They gathered two-phase flow pressure drop data from 18 published papers regarding with the boiling of R123, R134a, R22, R236ea, R245fa, R404a, R407C, R410a, $\mathrm{R} 507, \mathrm{CO}_{2}$, water and air. In the collected studies, the hydraulic diameters, $\mathrm{Re}_{\mathrm{h}}$ and $\mathrm{Re}_{\mathrm{g}}$ varied from 0.506 to 12 $\mathrm{mm}, 10$ to 37000 , and 3 to $4 \times 105$, respectively. The two-phase frictional pressure drops were calculated using the database by means of their prosed model. Their results showed that the results of the Lockhart-Martinelli method, Mishima and Hibiki correlation, Zhang and Mishima correlation and Lee and Mudawar correlation in the laminar region is nearly equal to each other, while the Muller-Steinhagen and Heck correlation is the most predictive one among the turbulent models. Modified version of Chisholm correlation demonstrated better predictively than those 
for turbulent flow and its average relative error was about 29\%. The proposed model and Muller-Steinhagen and Heck correlation gave nearly similar results and showed better agreement with the experimental database collected from literature. In the experimental investigation of Sun and Mishima [24], a new database including 2505 data points was obtained and compared with the thirteen prediction models for flow boiling heat transfer in minichannel with different tube diameters from 0.21 to $6.05 \mathrm{~mm}$. The results base on this study revealed that Chen method and the Chen-type correlations were not exactly coherent for minichannels; however, the Lazarek-Black correlation and the Kew-Cornwell correlation were the best of all. The authors proposed a new correlation based on the Lazarek-Black correlation associating with Weber number. Boudouh et al. [25] distinguished the local heat transfer coefficients and surface temperatures of a plate consist of vertically located 50 parallel rectangular minichannels with $800 \mu \mathrm{m}$ hydraulic diameter. By combining two benefits, decreasing the channel diameter and putting account of nanofluids that involves small quantity percentage nanoparticles, local heat transfer coefficient for convective boiling is investigated. It is clear from the figure that the local heat transfer coefficient decreased through the flow direction mainly due to the dry out as reported by the researchers. According to the experimental data of $\mathrm{Cu}$-water nanofluids local heat transfer coefficient, local heat flux and pressure drop are increased; surface temperature was decreased because of its high viscosity by comparison with base fluid at the same mass flux. Brix et al. [26] derived a one dimensional steady state numerical model in order to find out the efficiency of a minichannels evaporator with parallel ducts, with refrigerant $\mathrm{CO}_{2}$. During determination of the frictional pressure drop and heat transfer coefficients, common empirical correlations were used. The purpose of the study was to examine the consequence of non-uniform $\mathrm{CO}_{2}$ flow on the performance of the heat exchanger by numerical modelling. The outcome of the study was that, non-uniform refrigerant flow resulted in deterioration of the heat exchanger performance. Two parallel vertically located minichannels were modelled during the study, so, if the orientation and the number of the minichannels changes, the results may alter. Dutkowski [27] performed experiments on minichannels in order to achieve flashing procedure by acquiring relatively high-pressure drop with respect to ordinary ducts. The entrance of the $500 \mathrm{~mm}$ tall minichannels with $1.68 \mathrm{~mm}$ diameter is supercooled and its $200 \mathrm{~mm}$ region is warmed up. The flow rate of the working fluid varied from 200 to $450 \mathrm{~kg} \mathrm{~m}^{-2}$ with respect to varying entrance subcooling of 5 to $15 \mathrm{~K}$ and heat flux density of 1.7 to $60.3 \mathrm{~kW} \mathrm{~m}^{-2}$. The results were proffered on various boiling curves in furtherance to see the effect of flashing occurrence. Dutkowski [28] studied on horizontal stainless steel tubes in order to clarify the frictional pressure drop characteristics on minichannels and used air water blend for varying quantities from 170 to $7350 \mathrm{~kg} \mathrm{~m}^{-2} \mathrm{~s}^{-1}$. Moreover, the velocity ranges for air and water passing through the tubes is $0.2-7.4$ and $1.7-41.8 \mathrm{~m} \mathrm{~s}^{-1}$, respectively. The experimental outcomes are contrasted with the homogenous equilibrium model and dynamic viscosity coefficient is counted up according to 8 different correlations. As a result, the estimation of the two-phase pressure drop in $1.35 \mathrm{~mm}$ with conventional homogenous equilibrium model gave quite acceptable results. Pamitran et al. [29] investigated the pressure drop characteristics of several refrigerants (R22, R134a, R410A, R290 and R744) under different physical test conditions (heat flux, mass flux, saturation temperature) for horizontal stainless steel channels with different sizes. On the other hand, an assessment is made for these pressure drop characteristics based on the correlations in the literature. Furthermore, a contemporary model for predicting pressure drop is brought into existence by the help of several data obtained from the experiments. Ribeiro et al. [30] studied on a new evaporator design, which is suitable for smaller size cooling systems, and used to keep a laptop chip temperature under a certain value in the experiments. The system worked under changeable saturation temperatures and mass flow rates. As a result, rejecting substantial heat transfer rates is achieved with the refrigerant R600a. Therefore, the augmenting refrigerant flow rate led to enhanced heat transfer. Moreover, the test results showed quite acceptable results with the Zhang's correlations for determining average of heat transfer coefficient. Bang et al. [31] investigated the pressure influence of the boiling flow in stainless steel mini ducts of $1.73 \mathrm{~mm}$ diameter under a varying range of 2-16 bars pressure and used water as working fluid. The outcome of the study is that, there is not a remarkable effect of pressure on the heat transfer coefficient. Chen et al. [32] studied on horizontal thin ducts of $1 \mathrm{and} 2 \mathrm{~mm}$ in order to see the impact of the duct size on heat transfer for boiling saturated flows with refrigerant R410a. Outcomes based on the experiments indicate that mass flux and saturation temperature enhances, opening width reduces heat transfer. Moreover, according to the screened results of the experiments, mean bubble diameter is indirectly proportional with the mass flux and saturation temperature. Furthermore, prognosis is made with the correlations obtained by R134a and R407C. Copetti et al. [33] conducted experiments on a horizontal annular stainless steel channel with $2.6 \mathrm{~mm}$ diameter under varying heat flux (10-100 $\left.\mathrm{kW} \mathrm{m}^{-2}\right)$, mass flow rate (240-930 
$\left.\mathrm{kg} \mathrm{m}^{-2} \mathrm{~s}^{-1}\right)$ and saturation temperature $\left(12-22{ }^{\circ} \mathrm{C}\right)$ by using R-134a as refrigerant in order to comprehend heat transfer and pressure drop phenomena of the mini ducts. As the vapour quality increased, the heat flux and heat transfer relation tended to disappear and frictional pressure drop is reduced. Finally, different correlations are taken into account to determine the heat transfer coefficients; and it is seen that Kandlikar and Balasubramanian's model was the best-fitted one with the experimental results. Kaew-On et al. [34] studied on the flow boiling heat transfer characteristics of R134a in the aluminium multiport minichannels counter flow heat exchangers, which flowed hot waters outside. While heat fluxes varied from 15 to $65 \mathrm{~kW} \mathrm{~m}^{-2}$, system pressures varied from 4 to 6 bars and mass fluxes varied from 300 to $800 \mathrm{~kg} \mathrm{~m}^{-2} \mathrm{~s}^{-1}$. In addition, they compared experimental results with nine correlations, which can be found in literature. Furthermore, they suggested a correlation in order to determine heat transfer coefficient. They concluded that the flow-boiling regime was observed as nucleate boiling. In addition, they stated that the average heat transfer coefficient increased by $50-70 \%$, as number of channels decreased from 14 to 8 at the same test conditions. Wu et al. [35] experimentally investigated heat transfer and pressure drop of $\mathrm{CO}_{2}$ in twophase flow conditions. In the study, they used horizontal minichannels having hydraulic diameter of $1.42 \mathrm{~mm}$ and length of $0.3 \mathrm{~m}$. They performed experimental study in order to describe the heat transfer and pressure drop relying on the vapour quality in the tube. They created a databank containing 200 measurement points and checked their experimental data against widespread models. It was seen that nucleate boiling was dominant which relied on the heat flux and the saturation temperature at low vapour qualities. In addition, higher heat flux and higher saturation temperature caused an improvement of nucleate boiling which induced a rising activation of nuclei at the channel wall. They observed that heat flux had important impact on two-phase frictional pressure loss. $\mathrm{Li}$ and $\mathrm{Wu}[36]$ studied on adiabatic pressure loss in evapourative micro and minichannels. They gathered 769 data which contains comprehensive working parameters and channel diameters. These data was compared with five existing correlations. Among these correlations, the Muller Stein-Hagen and Heck model had the best prediction performance. In addition, it was seen that Bond number, which was, depend on channel measures and capillary variable was important. In addition, they did not consider impact of mass flux in two-phase multipliers, while they considered the surface tension impacts with including Bond number, which is distinct from normal channel. Oh et al. [37] researched the heat transfer of R22, R134a, R410a, $\mathrm{C}_{3} \mathrm{H}_{8}$ and $\mathrm{CO}_{2}$ flowing in circular tubes having diameters of $0.5,1.5$ and $3 \mathrm{~mm}$. They observed that mass flux and heat flux had significant influences on the heat transfer coefficient at high and low quality regions, respectively. They also presented that the heat transfer coefficient increased with increasing saturation temperature and decreasing tube diameter. In addition, the results of maximum heat transfer coefficient were obtained for $\mathrm{CO}_{2}$ among the tested fluids. Moreover, a new correlation having $15.3 \%$ mean deviation was proposed for heat transfer determination in small tubes. Ong and Thome [38] aimed to research impact of saturation temperature, heat flux, flow pattern, channel confinement, subcooling and fluid type on flow boiling heat transfer and critical heat flux. In the study, they used R134a, R236fa and R245fa refrigerants and single channels having diameters of 1.03, 2.2 and $3.04 \mathrm{~mm}$. They observed that the saturation temperature of the fluid had significant effect on two-phase heat transfer coefficient at isolated bubble and coalescing bubble flow regimes. For the same experimental conditions, the heat transfer coefficient increased with increasing mass flux. They also had seen that inlet subcooling temperature had no serious effect on heat transfer coefficient for different vapour qualities. As another result of the study, they derived a new correlation in order to determine critical heat flux of tested refrigerants flowing in rectangular multi channels, single circular channels and split flow rectangular multi channels. Saisorn et al. [39] investigated the effect of flow patterns on the heat transfer coefficient of R134a flowing in a circular minichannels. In the study, different flow patterns such as slug flow, throat- annular flow, churn flow; annular flow and annular-rivulet flow were taken into consideration. For these flow patterns, the variation of the heat transfer coefficient with vapour quality and heat flux was determined and compared with three-zone flow boiling model. They also noted that the three-zone flow-boiling model can be used for the determination of throat- annular and churn flow patterns besides slug flow pattern. Piasecka and Maciejewska [40] analysed flow structure and heat transfer of FC-72 during boiling in a minichannels with different orientations (vertical and horizontal). Authors have used liquid crystals to measure the temperature on the heating surface of the minichannels. This measurement later was used as a boundary condition to determine the heat transfer coefficient in the flow. Beck method and Trefftz functions were used to determine the temperature distribution along the heating and glass surface, respectively. It is found that the cork shape boiling structures become effective as the boiling develops. These structures also found to have different characteristics depending on the orientation of the system while the horizontal orientation found to be more stable than the vertical one. 
Experiments also confirmed that the void fraction and heat flux are proportional to each other and significant enhancement in heat transfer occurred at the onset of boiling in minichannels. Wu and $\mathrm{Li} \mathrm{[41]} \mathrm{compiled} \mathrm{a} \mathrm{database}$ covering 1672 experimental data points for investigating saturated critical heat flux in minichannels and microchannel. In the study, $\mathrm{BoRe}_{1}^{0.5}=200$ determined as macro to mini scale criterion since flow had different trends before and after this number. They separated data points as region $\mathrm{I}\left(\mathrm{L}_{\mathrm{h}} / \mathrm{d}_{\mathrm{he}} \leq 150, \mathrm{BoRe} \mathrm{l}_{\mathrm{l}}^{0.5} \leq 200\right)$ and region II $\left(\mathrm{L}_{\mathrm{h}} / \mathrm{d}_{\mathrm{he}} \leq 150, \mathrm{BoRe}_{1}^{0.5} \leq 200\right)$ and produced dimensionless number $\mathrm{We}_{\mathrm{m}} \mathrm{Ca}_{1}{ }^{0.8}$ demonstrating the influence of viscous force, surface tension and inertia on critical heat flux for region II. Moreover, they developed correlations for both regions and compared with the four different correlations in the literature. It was concluded that they developed correlation can predict $93.5 \%$ of water data and $95.9 \%$ of non-aqueous data in the range of $\pm 30 \%$. Farahani and Kowsary [42] numerically studied in order to determine local convective boiling heat transfer of pure water and nanofluid for transient and steady state conditions. In the study, water/copper mixture having concentration of 5,10 and $50 \mathrm{mg} / \mathrm{L}$ was considered as nanofluids. The space-variable heat transfer coefficient convective heat transfer coefficient and inversed heat conduction problem were determined by using sequential function specification method (SFSM). They investigated the variation of exact and estimated heat transfer coefficients with time for all tested fluids and observed that the convective boiling heat transfer coefficient can be estimated by means of SFSM, properly. Kaew-On et al. [43] performed experiments in order to clarify pressure drop of R134a flowing in 2 different multiport minichannels for flow boiling conditions. They used inner tube of double pipe heat exchanger as test section and investigated the influence of aspect ratio, mass flux, and saturation temperature and heat flux on frictional pressure drop. They also studied the components of pressure drop (frictional pressure drop, momentum pressure drop, sudden contraction pressure drop and sudden expansion pressure drop) and determined the dominant one as the frictional pressure drop with its ratio of $90-95 \%$. Moreover, it was seen that the frictional pressure drop increased with decreasing saturation temperature. They also compared the experimental results with the nine correlations given in the literature. Kaew-On and Wongwises [44] carried out experiments in order to determine heat transfer characteristics of R134a flowing in a multiport minichannels. Their manifold design can be seen in their work. They performed pressure drop and heat transfer experiments by using double pipe heat exchanger as test section. It was seen that mass flux had significant effect on frictional pressure drop rather than heat flux because in the liquid-vapour interface and the tube wall shear stress increased with increasing mass flux. They observed that heat transfer coefficient increased with increasing heat flux for different average qualities. In addition, they compared their experimental results with seven-heat transfer coefficient and six pressure drop correlations. As another results of the study, heat transfer coefficient and two-phase multiplier correlations were developed. Liu et al. [45] experimentally researched heat transfer of a hydrocarbon fuel of kerosene kind in minichannels for subcooled flow boiling conditions. They investigated the wall temperature at various pressures, mass flow rates and heat fluxes, the influence of pressure on heat transfer performance, the variation of the heat transfer coefficient with heat fluxes, mass fluxes and bulk fluid temperatures. In the experiments, it was seen that mass flux had no remarkable effect on the heat transfer coefficient. They also presented that fuel subcooling, pressure and heat flux had serious effect on the heat transfer coefficient. In addition, they proposed correlations, which can predict heat, transfer coefficient experimental results in the range of $\pm 10 \%$. Maqbool et al. [46] investigated the effect of tube diameter, mass flux, and vapour quality and saturation temperature on dry out of propane in vertical minichannels. Two circular minichannels having diameter of 1.224 and $1.70 \mathrm{~mm}$ were used as test tube in the experiments. They stated that the tube having bigger diameter had higher dry out heat flux for constant mass flux. It was also observed that there was not significant dependence between dry out heat flux and saturation temperature. In addition, they presented that dry out heat flux increased with decreasing vapour quality and increasing mass flux. As another result of the study, eight critical heat flux correlations given in the literature were compared with experimental results and the mean absolute deviations were in the range of $10 \%$ and $37 \%$. Mortada et al. [47] studied heat transfer characteristics of R1234yf and R134a flowing in rectangular minichannels having $1.1 \mathrm{~mm}$ hydraulic diameter, experimentally. In the study, they researched variation of the local heat transfer coefficient of R1234yf and R134a with vapour quality and heat flux for low mass flux conditions. It was seen that the mass flux and vapour quality had serious effect on the local heat transfer coefficient compared to heat flux. They observed that R1234yf showed 40\% higher the local heat transfer coefficient results compared to R134a for the same experimental conditions. They also investigated the effect of mass flux on critical heat flux. Moreover, they proposed a new correlation, which predicts experimental results in the range of $\pm 15 \%$. Anwar and Lahore [48] studied flow boiling heat transfer performance of R134a in vertical 
circular minichannels experimentally. Effect of heat flux on heat transfer coefficient, variation of heat transfer coefficient with mass flux and vapour quality and effect of system pressure on local heat transfer coefficient were investigated in the study. It was observed that the heat flux and system pressure showed significant effect on heat transfer coefficient compared to vapour quality and mass flux. In addition, experimental local heat transfer coefficients were compared with some researchers' correlations. Saisorn et al. [49] performed flow-boiling experiments in vertical and horizontal minichannels to get flow visualization and heat transfer data of R134a. They determined the local heat transfer coefficient for different flow patterns such as slug flow, throat annular flow, annular flow, churn flow, annular flow and annular-rivulet flow in vertical minichannels. Among these flow patterns, they suggested throat annular flow, churn flow and annular flow for applications because their high and stable heat transfer coefficients. They also investigated the effect heat flux, saturation pressure and mass flux on the heat transfer coefficient for both horizontal and vertical minichannels. Moreover, the experiments showed that R134a flowing vertical upward had a higher heat transfer coefficient compared to a horizontal one for higher mass fluxes. Finally, they compared their experimental results with macro-scale and micro-scale correlations. Copetti et al. [50] carried out an experimental study in order to investigate flow boiling and pressure drop of R600a flowing in a horizontal minichannels. Researchers compared the local heat transfer coefficient and frictional pressure drop of R600a and R134a for various vapour quality and mass flux. It was observed that the heat transfer coefficient and frictional pressure drop of R600a is higher than R134a under the same experimental conditions. They also revealed that the heat transfer coefficient was nearly constant at lower mass velocity and low heat flux and the frictional pressure drop increased with increasing mass velocity for R600a. Moreover, they compared the experimental results with correlations, which predict heat transfer coefficient and frictional pressure drop. Maqbool et al. [51] did experiments to investigate pressure drop and local heat transfer of propane in vertical circular minichannels for flow boiling conditions. It was observed that the two phase frictional pressure drop increases with increasing mass flux, vapour quality and heat flux. They also stated that heat flux and saturation temperature have a significant effect on the local heat transfer coefficient compared to mass flux and vapour quality. They revealed that the beginning of dry out decreases two phase frictional pressure drop and local heat transfer coefficient of propane for high mass fluxes. Moreover, they examined the performance of the pressure drop and local coefficient of heat transfer models with experimental data, which were divided as before, and after beginning of dry out. The correlations of Cooper and Müller-Steinhagen and Hack performed the best prediction performance for the heat transfer coefficient and pressure drop among the other correlations, respectively. Mikielewicz et al. [52] investigated liquid film dry out of R134a, R123, SES 36 and ethanol flowing in vertical minichannels. They revealed that the critical length becomes smaller with increasing heat flux for all test fluids. The effects of mass flux and critical heat flux on critical vapour quality were also studied for different mass fluxes, fluids and diameter. The results showed that the minichannels having a bigger diameter had lower critical vapour quality compared to a small one for the same mass flux. They developed a new empirical correlation for prediction of critical heat flux in minichannels and examined it with experimental results. Balavignesh et al. [53] performed a study in order to investigate the flow boiling heat transfer and pressure drop of n-Pentane flowing in a minichannels. They investigated the effect of heat flux on exit vapour quality and pressure drop for different mass fluxes. It was seen that exit vapour quality and pressure drop increased with increasing heat flux for the same mass flux. In the study, they also researched the change of heat transfer coefficient with vapour quality. Moreover, they compared their experimental results with other researchers' correlations and showed that they are in the range of $\pm 20 \%$. Kim and Jeong [54] studied the pressure drop of $\mathrm{CO}_{2}$ in smooth and micro rectangular grooved multiport minichannels, experimentally. In the study, they performed single (saturated liquid phase) and two-phase (adiabatic condition and constant heat flux) flow experiments. They revealed that the single-phase pressure drop of $\mathrm{CO}_{2}$ flowing in minichannels can be predicted by using Blasius correlation properly. For single-phase flow conditions, the tube having micro grooves had $30 \%$ higher pressure drop compared to smooth one. For two-phase flow conditions, the tube having micro grooves had higher pressure drop in the range of $10 \%$ and $45 \%$ compared to smooth one. Moreover, they compared the experimental results with the correlations for two-phase pressure drop and presented that the correlation of Mishima and Hibiki is suitable for the prediction of pressure drop in minichannels. Kim and Mudawar [55] presented a correlation for dry out incidence quality by using a large database. The database comprised of 13 working fluids, mass velocities $\left(29-2303 \mathrm{~kg} \mathrm{~m}^{-2} \mathrm{~s}^{-1}\right)$, hydraulic diameters $(0.51-6 \mathrm{~mm})$, and Boiling numbers $\left(0.31 \times 10^{-4}-44.3 \times 10^{-4}\right)$, liquid-only Reynolds numbers $(125-53,770)$ and reduced pressures $(0.005-0.78)$. They compared this database including 997 points with seven correlations given in the literature. Moreover, they 
observed that the correlation of Mastrullo presented the best dry out prediction of incipience quality performance with its lower mean absolute error. They stated that the developed correlation was successful for prediction of dry out incipience quality because of its overall mean absolute error of 12.5\%. Kim and Mudawar [56] proposed a new correlation for the prediction of pre-dryout two-phase heat transfer coefficient in minichannels and microchannel. They used 10,805 two-phase heat transfer coefficient data points including 18 different working fluids, hydraulic diameters (0.19-6.5), mass velocities (19-1608 $\left.\mathrm{kg} \mathrm{m}^{-2} \mathrm{~s}^{-1}\right)$, liquid-only Reynolds numbers $(57-49,820)$, flow qualities (0-1) and reduced pressures (0.005-0.69). In the study, these data were compared with four different correlations for macrochannels and nine different correlations for mini/microchannel. Among all correlations compared, Lazarek and Black and Liu and Winterton correlations performed the best prediction performance. They concluded that proposed correlation has the mean absolute error of $20.3 \%$ for overall data points. Brutin et al. [57] examined the effect of gravity level on flow boiling of HFE7100 in a minichannels by means of frictional pressure drop and local void fraction measurements. In the study, they considered three different gravity levels such as 1.8 $\mathrm{g}$ (hyper gravity), $1 \mathrm{~g}$ (normal gravity) and $\pm 0.05 \mathrm{~g}$ (microgravity). They observed that total and frictional pressure drop increases with the rise in gravity level. They investigated the variation of void fraction along the section for different mass velocities and gravity levels. It was observed that the void fraction increases with decreasing mass velocities and gravity levels. Moreover, they visualized the flow in minichannels for hypergravity and microgravity in order to clarify the film formation process in microgravity. Kim and Mudawar [58] presented a generalized method for two-phase frictional pressure drop gradient determination in minichannels and microchannel for flow boiling conditions. The database comprised of 9 working fluids, mass velocities (33-2708 $\left.\mathrm{kg} \mathrm{m}^{-2} \mathrm{~s}^{-1}\right)$, hydraulic diameters $(0.349-5.35 \mathrm{~mm})$, liquid-only Reynolds numbers (156-28010) and reduced pressures (0.005-0.78) were taken into consideration in the study. The correlations can be used for prediction of two-phase frictional pressure drop were compared with the database and the correlation of Mishima and Hibiki performed the best prediction performance with mean absolute error of $27.6 \%$. Moreover, they proposed a new two-phase frictional pressure drop gradient correlation having overall mean absolute error of $17.2 \%$ and tested its performance for different flow regimes. Anwar et al. [59] experimentally investigated flow boiling and dryout of R152a in a vertical minichannels. Heat flux found to have a major impact on the heat transfer while mass flux and vapour quality had slight influence over it. An increase of heat transfer was observed with increasing system pressure. While small differences due to physical properties were observed between R152a and R134a, they reported to have similar results which lead to the conclusion that former could be a replacement for the latter. Among present models, Mahmoud and Karayiannis and $\mathrm{Wu}$ et al. are the best to predict their data for heat transfer coefficient and CHF respectively. Higher mass flux caused higher CHF while R152a has considerable higher CHF than R134a. Flow boiling of R245fa in medium saturation temperatures was also researched by Charnay et al. [60] in another study. Heat flux found to have an enhancer effect on the overall heat transfer, which is observed for the saturation temperature as well. The authors concluded that the higher saturation temperature results in thermophysical changes that cause an increase in nucleation sites, which leads to higher, nucleate boiling heat transfer. However, this type of boiling only observed for intermittent flow while convective heat transfer takes over in annular flow. The authors also compared their results with correlations from the literature and found most of the methods are in match with experimental results. Choi et al. [61] carry out investigation of heat transfer of evaporation performance of $\mathrm{CO}_{2}, \mathrm{NH}_{3}, \mathrm{C}_{3} \mathrm{H}_{8}$ and $\mathrm{R} 1234 \mathrm{yf}$ in two mini-scale tubes and development of a new correlation. Due to channel geometry and thermophysical properties, mass flux and vapour quality are found to be ineffective on heat transfer rate, which leads to a conclusion that the nucleate heat transfer is the main mechanism that drives the heat transfer in low quality flow regions. However, heat flux was found to be an important factor in these regions, and high saturation temperature was found to have a positive influence over all flow regions. Small diameter tubes show higher heat transfer performance due to increased contact surface. The authors proposed a new multiphase multiplier and heat transfer coefficient, which showed good agreement with current experiments. $\mathrm{CO}_{2}$ is also found to be the highest performer of all experimented refrigerants in the study. Xu et al. [62] study frictional pressure drop of R134a in a minichannels under hypergravity. All experiments are carried out on a centrifugal acceleration assembly that carries experimental setup on itself and determination of the effects of hypergravity over pressure drop is aimed. Experiments revealed that the hypergravity conditions do not have any significant impact on the pressure drop since experiments under normal gravity conditions showed similar results in most cases although some distinct results are also observed under certain conditions. In high quality region of flow, frictional pressure drop observed in hypergravity is higher than normal gravity conditions while opposite observation is valid in low quality region 
although dissimilarity also occurred on some experiments. Under hypergravity conditions, mass flux, heat flux, saturation temperature and vapour quality also showed the same effects as in normal gravity conditions on the frictional pressure drop. Piasecka [63] investigated the performance of 12 different heat transfer coefficient correlations used for flow boiling in different oriented minichannels. Author stated that the some of the inspected correlations only give results to a specific type of orientation. New correlations for saturated flow boiling and subcooled flow boiling are also generated and showed satisfactory results with the experiments while latter correlation is in high agreement with Dittus-Boelter correlation developed for single-phase flows. The importance of the implementation of the surface parameter is also noted and the author makes recommendation regarding this aspect. Xu et al. [64] investigated heat transfer in flow boiling in minichannels under hypergravity as a continuation of their previous work. Unlike pressure drop results, hypergravity is found to have considerable impact on the heat transfer, and heat transfer coefficient is resulted in higher values as the gravity acting on the flow is increased. This phenomenon is linked to the alteration of flow pattern and flow distribution by the authors. The deviation occurred in heat transfer rate due to hypergravity is also found to vary with saturation pressure although no certain rule is found between these two parameters in this aspect. 11 correlations developed for normal gravity conditions were tested against the data acquired during the experiments and 6 correlations found to be in agreement with the data with errors under $30 \%$.

\section{Microchannel Geometry}

The works in microchannel on this subject is summarized from literature. Yen et al. [65] examined the convective boiling of HCFC123 and FC72 in 0.19 , and $0.51 \mathrm{~mm}$ ID tubes. The uncertainty interval of the heat transfer coefficient in the microtubes was as little as $\pm 10 \%$ due to the meticulously designed temperature measurement and the heat loss compensation. They collected results from experiments such as; at low heat and mass fluxes, the liquid superheat up to $70 \mathrm{~K}$ over the saturation temperature was observed. The other one is, in the saturated boiling regime; when the vapour quality was increasing, the heat transfer coefficient was monotonically decreased but independent of the mass flux. The heat transfer coefficient for various diameters, mass flux and heat flux can be studied for different quality values. Steinke and Kandlikar [66] performed experiments to investigate the control of dissolved gases and impacts of them on heat transfer. In addition, they performed a study related to the pressure drop during the flow of water in a microchannel. In the experiments, six parallel copper microchannel were used and hydraulic diameter of each one was $207 \mu \mathrm{m}$. While boiling was performed with water, nucleation was observed at a surface temperature of $90.5^{\circ} \mathrm{C}$ and the dissolved oxygen content was $8.0 \mathrm{ppm}$ with the pressure of $1 \mathrm{~atm}$. On the other hand, when the content of dissolved oxygen was 5.4 and $1.8 \mathrm{ppm}$ the nucleation was not observed. For this case, the nucleation was observed when the temperature reached $100{ }^{\circ} \mathrm{C}$ at the 1 atm pressure. They stated that the cause of the slight reduction in heat transfer was the beginning of bubbles in the $8.0 \mathrm{ppm}$ case, because, bubble layer generated an insulating layer on the heater surface. Thome et al. [67] proposed a model called a three-zone flow-boiling model, to define evaporation of elongated bubbles in microchannel. The schematic representation of three zone can be investigated. They described that the new model exemplified the variation of heat transfer coefficient according to strong cycle, bubble frequency, the liquid film formation thickness and the minimum liquid film thickness at dry out. Yun et al. [68] experimentally studied the convective boiling heat transfer and dry out fact. The working fluid was $\mathrm{CO}_{2}$ and channels were rectangular with hydraulic diameters range from 1.08 to $1.54 \mathrm{~mm}$. The experiments were performed by diversifying the mass flux of $\mathrm{CO}_{2}$ between $200-400 \mathrm{~kg} \mathrm{~m}^{-2}$ $\mathrm{s}^{-1}$, heat flux between $10-20 \mathrm{~kW} \mathrm{~m}^{-2}$ during conserving the saturation temperature at 0.5 and $10{ }^{\circ} \mathrm{C}$. The tests' results indicated that when comparing the $\mathrm{CO}_{2}$ and refrigerant $\mathrm{R} 134 \mathrm{a}$ the average of heat transfer coefficient of $\mathrm{CO}_{2}$ was $53 \%$ higher than refrigerant. The impacts of heat flux on heat transfer coefficient notably differed from mass flux. Dryout process has become more prominent while the mass flux has increased. The heat transfer coefficients increased up to $5 \%$ and $31 \%$ by changing the hydraulic diameter from 1.54 to $1.27 \mathrm{~mm}$ and from 1.27 to $1.08 \mathrm{~mm}$, respectively. They used the Cooper and the Gorenflo models in order to predict nucleate boiling heat transfer coefficients and showed that these correlations having mean deviations of $21.7 \%$ and $21.2 \%$, respectively. $\mathrm{Li}$ et al. [69] investigated heat transfer in microchannel for laminar flow at Reynolds number ranging from 80 to 2400 , both experimentally and numerically. Two different microtubes materials namely smooth fused silica and stainless steel were used to investigate the friction factor for laminar flow. The inner diameter of microtubes varied from 300 to $1570 \mu \mathrm{m}$. In this study, the authors compared the experimental friction factors and the conventional theory for both materials. The results of this study were plotted graphically. In these plots the local Nusselt number 
distribution, which considered the numerical and experimental determined values, and the bulk temperature distribution along the axial direction of the tube with the different Reynolds number were presented. The second part of the paper of Qi et al. [70] deal with the heat transfer characteristics and critical heat flux (CHF). To be more clearly, the influences of heat flux, mass flux, and pressure and tube diameter on the flow boiling heat transfer coefficients are studied. In this study, two-phase flow region was stated because of the heat transfer mechanism. These were nucleate boiling dominated region for low mass quality and the convection evaporation dominated region for high mass quality. A new correlation was proposed by the authors expressed by Co, Bo, We, Kp and X. The new correlation yielded good fitting for 455 experimental data with a mean absolute error (MAE) of $13.7 \%$. For current micro-tubes except for $1.931 \mathrm{~mm}$ tube. From the results of this study, the critical heat flux and critical mass quality were higher than conventional channels. In addition, an increment in the critical heat flux gradually resulted in the decrease of tube diameter. Lee and Pan [71] investigated the eruptive boiling heat transfer in the silicon-based microchannel, which were made of SOI (Silicon on Insulator) water and produced using bulk micromachining and anodic bonding processes. A high-speed camera was used both to visualize two-phase flow during boiling conditions and to measure the temperatures at the heating surface, inlet and outlet chambers as well as pressure drop from inlet to outlet chambers in the microchannel. The authors stated that eruptive boiling was a form of rapid bubble nucleation subsequently the bubble merged with a slug bubble downstream in a short distance or evolved to a slug bubble additionally may be predicted with nano sized cavities. An experimental investigation on flow boiling heat transfer carried out by In and Jeong [72]. In this study, the authors used a circular microchannel with the inner diameter of $0.19 \mathrm{~mm}$ with refrigerants R123 and R134a. The reasons of the selection of these refrigerants were that they had significant differences of properties at ambient saturation temperature, such as saturation pressure, surface tension and liquid viscosity. In the experimental study, the authors investigated the heat transfer trends with the different parameters, heat fluxes $\left(10,15,20 \mathrm{~kW} \mathrm{~m}^{-2}\right)$, mass fluxes $(314,392,470 \mathrm{~kg}$ $\left.\mathrm{m}^{-2} \mathrm{~s}^{-1}\right)$, vapour qualities (0.2-0.85) and different saturation pressures for each refrigerant. Then effects of these parameters on the heat transfer trend, and its physical significance in flow boiling of micro-channels were discussed. Roday and Jensen [73] studied to obtain flow boiling critical heat flux data in single stainless steel microtubes with diameters from 0.286 to $0.700 \mathrm{~mm}$ over a wide range of mass fluxes, inlet subcoolings, and exit pressures for water and R123. For the single-phase studies in microtubes, with R123 and water, it was found from the study that the pressure drop characteristics were consistent with conventional sized channels in laminar flow, however there was a marked inconsistency in the heat transfer characteristics where $\mathrm{Nu}$ was under predicted at lower Re and over predicted at higher Re. The critical heat flux condition in experiments with water, as well as $\mathrm{R} 123$, was marked by a sharp rise in wall temperature towards the exit of the heated section. The wall superheat at the onset of $\mathrm{CHF}$ for R123 tests varied from about 11 to $35^{\circ} \mathrm{C}$. For most of the water CHF tests, the wall superheat was between 3 and $25^{\circ} \mathrm{C}$, but for data at lower inlet subcoolings, very high wall superheats $\left(50-60^{\circ} \mathrm{C}\right)$ were seen before the characteristic CHF occurred. It was seen that the CHF condition were strongly affected by flow patterns with different operating parameters. The mass flux at fixed exit quality led to increase of CHF for saturation conditions. The authors stated that a decrease in the CHF resulted from an increase in quality in the subcooled region, but as qualities approached zero, this trend was reversed, and the CHF increased with quality into the saturated region. Shiferaw et al. [74] carried out a detailed comparison of flow boiling heat transfer results in a stainless steel tube of $1.1 \mathrm{~mm}$ internal diameter with three-zone flow model. R134a was used as working fluid. These parameters were varied in the range of mass flux $100-600 \mathrm{~kg} \mathrm{~m}^{-2} \mathrm{~s}^{-1}$, heat flux $16-150 \mathrm{~kW} \mathrm{~m}^{-2}$ and pressure 6-12 bar. As the result of heat transfer coefficient increased with heat flux, system pressure was indicated experimentally. When the quality was less than about $50 \%$ for low heat and mass flux values, it did not change with vapour quality. The mass flux effect was observed. It was found that for vapour quality values greater than $50 \%$ and at high heat flux values. However, the heat transfer coefficient does not depend on heat flux and decrease with vapour quality. Therefore, this condition could be happened by dryout. The experimental results was predicted fairly well by the three-zone evaporation model at relatively low pressure. A discussion critically examined the sensitivity of the performance of the model to the three optimised parameters (confined bubble frequency, initial film thickness and end film thickness) and some preliminary investigation relating the critical film thickness for dryout to measured tube roughness. Awad and Muzychka [75] used three incomparable models in order to simulate two-phase flows in microchannel and minichannels. The first method introduces a new description to two-phase viscosity by the help of one-dimensional analogy between two phase flow viscosity and porous media thermal conductivity. The second method is a semi theoretical method, which proposes determining two phase frictional 
pressure gradient using asymptotic analysis. The last method is composed of elementary precepts, which are derived for minichannels and microchannel, in order to procure rational connections for two-phase frictional pressure gradient. As a result, if the model is homogenous the first method, and if the model is separate the second and third models are appropriate during estimation of the two-phase frictional pressure drop in microchannel and minichannels. Celata et al. [76] experimentally investigated the heat transfer features of the single horizontal circular microchannel with 102, 480 and $800 \mu \mathrm{m}$ diameters by using overcooled flow boiling of FC72 as working fluid. The experiments were conducted for varying heat and mass fluxes and convective heat transfer coefficients were figured out in each flow. Kandlikar [77] investigated the scaling impacts of inertia, surface tension, shear, gravity, and evaporation momentum forces for working fluids water and FC77. Also, it is mentioned that two phase boiling refrigeration systems has an observable supremacy on single phase systems due to their low pressure drop levels, which led to an increase in the efficiency. Moreover, surface tension and evaporation momentum forces are main factors in microscale. Ali and Palm [78] performed experiments on $220 \mathrm{~mm}$ long stainless steel ducts with 1.22 and $1.7 \mathrm{~mm}$ diameters in order to see dryout effects on microchannel by using R134a as refrigerant. The ranges for mass flux is $50-600 \mathrm{~kg} \mathrm{~m}^{-2} \mathrm{~s}^{-1}$, heat flux is $7-156 \mathrm{~kW} \mathrm{~m}^{-2}$ and vapour quality is $0.5-1.2$ during the experiments carried out on two different saturation points $27 \square \mathrm{C}$ and $32 \square \mathrm{C}$. The results of the studies revealed that consequences of the tests are coherent with the literature. Moreover, it is clearly seen in both channels that vapour quality is indirectly proportional with the mass flux. Choi and Kim [79] carried out experiments on rectangular ducts with varying dimensions and hydraulic diameters (141, 143, 304, 322 and $490 \mu \mathrm{m})$. Several homogenous and separated flow correlations were discussed and a new one was proposed. In order to provide a two-phase flow, water and nitrogen were used on different varying velocities from 0.06 to $1 \mathrm{~m} \mathrm{~s}^{-1}$ and from 0.06 to $72 \mathrm{~m} \mathrm{~s}^{-1}$ respectively. Experimental results showed that flow pattern is the most important factor influencing the pressure drop characteristic of the flow. By the help of proposed homogenous and separated models, error values are improved $13.2 \%$ and $11.1 \%$ respectively. Costa-Patry et al. [80] conducted experiments on an evaporator of 135 mini ducts with $85 \mu \mathrm{m}$ width and $560 \mu \mathrm{m}$ height with the use of refrigerants R236fa and R245fa of varying flow rate rates. The heat transfer procedure was uniform along the flow due to 35 local heaters. When the heat flux value of wall exceeds $45 \mathrm{~kW} / \mathrm{m}^{2}$, heat transfer that is diminished until bubble merging started to step up again. Several correlations were performed for estimating the heat transfer coefficient and Thome's three-zone method was the best-fitted one among them. Ducoulombier et al. [81] studied on pressure drop characteristics of an annular stainless steel tube with $0.529 \mathrm{~mm}$ diameter and used $\mathrm{CO}_{2}$ as working fluid. The range of saturation temperature is from -10 to $5{ }^{\circ} \mathrm{C}$ and mass flux is from $200-1400 \mathrm{~kg} \mathrm{~m}^{-2} \mathrm{~s}^{-1}$ during the isenthalpic experiments. This study will be useful for microsystems due to its investigation of a narrow tube. Several correlations have examined in order to find the best-fitted model to the experimental study. Finally, homogenous model gave the most convenient results with the tests carried out. Ducoulombier et al. [82] studied on heat transfer characteristics of an annular stainless steel tube with $0.529 \mathrm{~mm}$ diameter and used $\mathrm{CO}_{2}$ as working fluid. The range of saturation temperature varied from -10 to $0{ }^{\circ} \mathrm{C}$, mass flux $200-100 \mathrm{~kg} \mathrm{~m}^{-2} \mathrm{~s}^{-1}$ and heat flux $10-30 \mathrm{~kW} \mathrm{~m}^{-2}$. According to the experimental results, considerably high quantities of heat transfer values are achieved beside the flows with the high saturation temperature and wider ducts. Two regions were observed about the boiling number characterizes. The critical value for boiling number is $1.1 \times 10^{-4}$. Wu et al. [83] developed a correlation in order to determine saturated critical heat flux in single and multi-channels. They comprised a database with 629 experimental data including different fluids, reduced pressures, hydraulic diameters, length/diameter ratios, mass fluxes and exit qualities. They also investigated the prediction of critical heat flux performance of five different empirical correlations given in the literature by using database. It was also observed that the influence of length/diameter ratio is nearly not important for $\mathrm{L}_{\mathrm{h}} / \mathrm{d}_{\mathrm{he}}>150$ conditions and boiling number at critical heat flux reduced significantly with a slight increase of length/diameter ratio in case of length/diameter ratio 50. Moreover, their developed correlation was predicted experimental data in the range of $\pm 30 \%$. Liu et al. [84] researched boiling heat transfer performance of co-current and counter-current silicon based micro channel heat exchangers, experimentally. They aimed to design a micro channel heat exchanger for reformed methanol fuel cell. In the heat exchanger, methanol was heated by helium and two-phase flow pattern were investigated. After heat transfer experiments, they concluded that the countercurrent micro channel heat exchanger was more convenient for construction of reformed methanol fuel cell system. From the point of efficiency, co-current and counter-current designs performed the maximum values as 0.85 and 0.90 , respectively. As another result of the study, it was presented that the efficiency of counter one was seriously influenced by mass flux. Farahani et al. [85] experimentally studied the flow boiling heat transfer of R245fa and 
R1234ze (E) refrigerants flowing in flat aluminium extruded multiport tube. In the study, the vertical multiport tube having 7 channels was used and the effects of saturation temperature, heat flux, vapour quality and mass flux on flow boiling heat transfer were investigated. They also proposed a method in order to reduce experimental data by using heat transfer relationship between the heating water and evaporating refrigerant flows for boiling conditions. Before two-phase flow experiments, they performed single-phase experiments with R1234ze (E) and determined friction factor and mean Nusselt number for validation. In the two-phase flow experiments, they observed that the heat transfer coefficient increased with increase of heat flux, saturation temperature, vapour quality and mass flux for both R245fa and R1234ze (E). Moreover, the variation of heat flux, wall, heating water and refrigerant temperatures along the channel was investigated. They also compared the experimental results with well-known correlations given in the literature in order to evaluate prediction performance of them. Mahmoud and Karayiannis [86] compared the experimental flow boiling heat transfer coefficient of R134a flowing in microtubes with different micro and macro scale models and correlations. They used a large experimental database having different tube diameter, tube length, mass flux and system pressure. The correlation of Gungor and Winterton showed the best prediction performance among the other macro scale correlations with the prediction of $45.7 \%$ for all data. The correlation of Mahmoud and Karayiannis performed the best prediction performance among the other micro scale correlations with the prediction of $87.3 \%$ for all data. Moreover, they developed a new local and average of heat transfer coefficient correlation by using 5152 data points, which can predict $92 \%$ of all data. Kaya et al. [87] carried out flow boiling experiments with microtubes having different diameters for high mass flux condition. In the experiments, they used de-ionized water and investigated the effect of mass velocity on critical heat flux at different heated length/inner diameter ratio. They observed that the critical heat flux diminished with increasing heated length/inner diameter ratio. As another result of the study, they revealed that mass flux was very important parameter for critical heat flux in micro scale contrary to macro scale flow. They also developed a new correlation for prediction of critical heat flux determination, which can predict experimental data in the range of \pm $30 \%$. Del Col et al. [88] studied convective boiling of R134a and R32 flowing in a single circular microchannel, experimentally. Unlike the other studies, they provided the heat flux by using the secondary heating fluid (water) instead of Joule effect heating. According to their results, R32 presented higher heat transfer coefficient compared to R134a for the same experimental conditions. The variation of water, wall and saturation temperatures along the tube length during a boiling process of R134a was investigated. Increase in wall temperature at $120 \mathrm{~mm}$ was due to the wall dryout according to the authors since the difference between wall and saturation temperature increased while local heat flux decreased. They also observed that mass flux has no serious effect on the heat transfer coefficient. For the same vapour quality, the heat transfer coefficient increases with increasing heat flux. Moreover, they compared experimental results with the four correlations given in the literature. Among the correlations, the correlation of Dupont et al. performed the best experimental of heat transfer coefficient performance. Liu et al. [89] experimentally investigated the effect of upstream compressibility on boiling heat transfer in microchannel. In the study, they used water and n-hexane as working fluids. They researched the influence of upstream buffer volume on pressure drop and showed that the pressure drop reduces with increasing buffer volume for different mass fluxes. Moreover, the effect of upstream compressibility on heat transfer coefficient was studied by using water and $0.9 \mathrm{~mm}$ multiblock apparatus. It was observed that the heat transfer coefficient is affected by buffer volume magnitude at around the onset of boiling. They also presented that the heat transfer coefficient stays the same for different qualities in case of soft inlet condition. Kabova et al. [90] numerically investigated the heat transfer and evaporation of a shear-driven liquid film by gas in a microchannel with heater on one side. Water and nitrogen are selected as liquid-gas pair in their study. Vapour concentration in nitrogen, temperature distributions in liquid-gas and surface deformation induced on the liquid by gas motion are identified under different flow velocities. Analyses showed that the evaporation of the vapour into the gas is occurred by means of forced convection and diffusion while diffusion is the major way of transportation at low Reynolds numbers. Liquid film thickness and dimensionless maximum temperature are found to diminish with increasing of Reynolds number. In addition, rupture risk of liquid film is increased in higher Reynolds numbers. Lowest film thickness was calculated to be at the end of the heater element, which had the highest probability of dry patch formation. Rao et al. [91] used a method to measure the surface temperature of a microstructure in high frequency interval to investigate the local heat transfer transition. Experiments showed that nearly $30000 \mathrm{~K}$ temperature changes occurred that lead to the conclusion that the heat transfer coefficient may change in excessive amounts in bubble formation cycle. Observed average heat transfer coefficients in these cycles are reported to be 2 or 3 times higher than those in 
micro domain. In addition, it is found that the formation of large bubbles have higher effect on heat transfer coefficient than the single bubble nucleation. Mirmanto [92] experimentally investigated the flow boiling of water in oxygen-free copper microchannel. Author made valuable examination of the linear pressure drop assumption in boiling in microchannel. Experiments revealed that the assumption is not valid at higher heat fluxes due to the increased bubble generation and non-uniform nucleation site distribution throughout the tube as reported. However, the author at low-pressure drop gradients recommends using of linear pressure drop assumption. Flow boiling inside a $500 \mu \mathrm{m}$ microchannel with water is experimentally investigated by Lim et al. [93]. Results showed that the mass flux has no effect on the heat transfer and nucleate boiling is the predominant way of boiling in the microchannel. New annular flow transition criteria based on Froude number and quality and an empirical heat transfer coefficient correlation were developed by authors and developed correlation did not agree well with the existing data in the literature.

\section{Bubble dynamics inside minichannels and microchannel}

A common entryway to the fundamental boiling flow phenomena may be directed regarding with the bubble departure diameter. One of unpredictable features of this phenomena is about sudden change of phases especially from liquid to boiling process, and comparison of the minimum dimensions of active bubbles are considered to the channel size. These ones in a heated channel flow are the bubbles moving from their beginning positions. When they start moving, they cause a disturbance in the flow, enhance heat transfer from the wall, and grow or forced by other bubbles. It should be noted that it is possible for anyone to use the bubble departure diameter in nucleate pool boiling as a characteristic parameter.

Peng et al. [94] examined the role of perturbations on the dynamics of clusters and analysed the impacts of internal and external perturbations. The development of clusters could be depressed by occurrence of internal perturbations. The external perturbation to clusters reveals the pressure waves, which are reflected from the channel wall. A model for the occurrence of fictitious boiling was recommended. Lee et al. [95] experimentally studied the bubble dynamics for convective boiling in a single trapezoidal microchannel. The selected hydraulic diameter was $41.3 \mu \mathrm{m}$. They used the high-speed digital camera to observe the bubble nucleation, frequency and departure size as shown for different timesteps 10. According to the result of this study the bubble nucleation may be estimated from the usual model with micro sized cavities. The bubble growth rate is from 0.13 to $7.08 \mu \mathrm{m} \mathrm{m}^{-1}$ $\mathrm{s}^{-1}$. In some cases, the growth rate changed from 72.8 to $95.2 \mu \mathrm{m} \mathrm{m}^{-1} \mathrm{~s}^{-1}$. The bubble frequency in an ordinary sized channel is comparable to that in the microchannel. $\mathrm{Li}$ et al. [96] experimentally studied the bubble dynamics for convective boiling in two parallel trapezoidal microchannel. The selected hydraulic diameter was $47.7 \mu \mathrm{m}$. The bubble growth and departure was generally similar to in a single channel according to the results. In that, the growth of bubbles was linear in general. The surface tension and drag by the reason of bulk two-phase govern their departure. The growth of bubble in slug flow was also examined. The tests' result showed that the bubble growth was in the axial direction both forward and backward. The length increased exponentially because of evaporation of the thin liquid film. The liquid film was between the bubble and heating wall. Nevertheless, the exponent's coefficient was much smaller than caused by evaporation, because of the limitation impact of liquid pressure around the bubble. Kenning et al. [97] studied the bubble growth in a capillary tube closed at one end and vented to the atmosphere at the other. The authors used the water as the test fluid. The authors measured the rate of axial growth and the varying pressure at the closed end experimentally then they used these measurements to investigate the bubble growth applicable in simplified one-dimensional models in microchannel. The authors highlighted that more attention is required to modelling features such as the possibility of "roll-up" of the liquid film due to a large dynamic contact angle. Dong et al. [98] performed simulations called non-equilibrium molecular dynamics (NEMD). They used the Freon R141b in simulations as a real fluid. The approach was based on annular flow method analysis. The purpose of this study can be determined as investigation of micro and nano scale liquidvapour interfacial phenomena. The type of cell which simulations were carried out was cuboid and a temperature gradient was set at both ends. The presented and discussed cases are heat flux, density, surface tension profiles and the temperature distribution of the simulated cell. According to the simulations' results, the saturated temperature and the superheat degree directly affect the characteristic of the liquid-vapour interface. Mukherjee and Kandlikar [99] studied the growth of a vapour bubble inside a microchannel during flow boiling with restrictions located at the channel inlet. The numerical study was based on the previously experimental data obtained by one of the authors. The authors observed that the rate of bubble growth lead to decrease the open area with $4 \%$ at the channel 
inlet resulted in higher velocity inlet. The incoming high speed liquid is obstructed by the nucleating bubble resulting in a zone of high pressure at the upstream end of the bubble. To be effective, the area ratio had to be quite small resulting in increased pressure drop to prevent flow instabilities and pressure rise inside the microchannel owing to accelerating vapour plugs. Barber et al. [100] conducted experiments for better understanding of the boiling procedure in microchannel. The study is elaborated by visualization and two-phase flow analysis. In order to understand the channel confining influence on bubble enlargement and accordingly pressure fluctuations, a boiling process in a rectangular cross sectional microchannel with $727 \mu \mathrm{m}$ hydraulic diameter is stimulated by using refrigerant $\mathrm{FC} 72$. In the study, a special case with uniform heat flux and constant inlet liquid mass flow rate conditions is handled. Unconfined bubble growth $\left(\mathrm{d}_{\text {bubble }}<<\mathrm{d}_{\mathrm{i}}\right)$, partial bubble confinement $\left(\mathrm{d}_{\text {bubble }} \approx \mathrm{d}_{\mathrm{i}}\right)$ and full bubble confinement $\left(\mathrm{d}_{\text {bubble }} \approx \mathrm{w}_{\mathrm{i}}\right)$ are the three base steps of bubble sputtering. The developing bubbles in the microchannel result in choking up the conduit, which causes pressure fluctuations either at the entrance or exit of the microchannel. Fu et al. [101] studied on vertical minichannels covered with a heater with varying diameters between 1.3-1.5 mm experimentally accompanying with the numerical work. The goal of the study was to observe behaviour of the bubbles in the boiling flow and know more about flow model and the concerned heat transfer coefficient. The study showed that tube diameter is independent of bubble departure. On the other hand, heat transfer features of minichannels are much more preferable to macrochannels. Mukherjee et al. [102] numerically investigated growth of vapour bubble in microchannel for flow boiling conditions. In the study, they used square microchannel having hydraulic diameter of $0.229 \mathrm{~mm}$ and water as working fluid. They performed numerical and experimental studies in order to determine bubble growth rate and bubble shape and compared them. Moreover, the effect of the surface tension and contact angle at walls, the wall superheat and Reynolds number were searched. Among these parameters, the contact angle was the most effective parameter for bubble growth rate and the surface tension had little impact on it. They observed that the wall heat transfer improved with increasing wall superheat. As another result of the study, the maximum wall heat transfer and maximum bubble growth rate were detected at bubbles having the lowest contact angle. Wang and Sefiane [103] studied formation and progression of a single bubble inside micro-gaps and microchannel flow by using FC72 and n-pentane as working fluid. In micro-gap experiments, bubble growth rate found to be consisted of linear and exponential parts depending on the bubble size. Increase of gap width and superheat temperature of the heating surface decreased the duration of the linear growth part therefore increased the bubble growth rate. However, this phenomenon only observed for n-pentane since FC-72 properties are significantly different. This observation is resulted in a conclusion that the bubble growth is fluid dependent. In flow boiling experiments, bubble growth rate found to increase with increasing heat flux, which resulted in quick evaluation of exponential growth part. Channel depth was also identified as a factor for bubble length while mass flux had nearly no effect on bubble geometry. In their numerical study, Pattamatta et al. [104] investigated the effects of Reynolds number, wall superheat, bubble size and Capillary number to the growth and coalescence of Taylor-Bubbles in FC72 flow boiling in a square minichannel. Open FOAM CFD (Computational Fluid Dynamics) code with finite volume model was selected as the simulation of the phenomenon and VOF was used to monitor the liquid-gas interface. In higher Reynolds number and higher wall superheat simulations, bubble coalescence time was found to be lower and higher superheat of heater wall resulted in the observation of dry-out. Existing of a higher bubble upstream of a smaller bubble also was found to have shorter coalescence time while no coalescence occurred during contrary conditions. Different bubble sizes also were found to have negligible influence on heat transfer. Capillary number affected the coalescence in different ways; at higher Capillary number, cycle of coalescence and breakout occurred between bubbles while no merger observed at lower Capillary number. Reynolds number, wall superheat and bubble size were found to have the effect on the amount of the evaporated FC72 while heat transfer was found to depend only on the Reynolds number and wall superheat. Gong and Cheng [105] applied numerical solution to the microchannel to investigate the effect of contact angle, inlet velocity and heated surface area on the saturated flow boiling using lattice Boltzmann method. Authors concluded that the velocity has influence over the departed bubble size while the effect of the contact angle value of the fluid is negligible. Nusselt number dependence on the Reynolds number, superheat temperature and contact angle were investigated and an increase in contact angle resulted in lower Nusselt numbers as opposed to the former two parameters. Simulation results also revealed that the nucleation time and temperature increase with increasing fluid velocity. However, authors also reported that the unrealistic pressure jumps were observed during the analysis, which concluded to be the reason of using real gas equation of states in the model. 


\section{Flow pattern and visualization in minichannels and microchannel}

Many experimental works have validated and enhanced the flow regimes, empirical correlations and transport mechanisms whose predictability performance can be considered as successful in limited applications. On the other hand, their compatibility with experiments can be revealed by the usage of empirical constants instead of theoretical intensive aspects. It should be noted that examining the flow regimes and transport mechanisms of evaporation in mini and microchannel are significant before developing models or choosing appropriate correlations.

Satitchaicharoen and Wongwises [106] visualized the flow patterns of vertical upward gas-liquid two-phase flow in mini gap for superficial velocities, using air-water, air $20 \mathrm{wt}$ \% glycerol solution and air $40 \mathrm{wt}$ \% glycerol solution as working fluids. The rectangular test sections had $20 \mathrm{~mm}$ x $2 \mathrm{~mm}, 40 \mathrm{~mm}$ x $1 \mathrm{~mm}, 40 \mathrm{~mm} \times 2 \mathrm{~mm}, 40$ $\mathrm{mm} \times 3 \mathrm{~mm}$ and $60 \mathrm{~mm} \times 2 \mathrm{~mm}$ dimensions. In addition, they had an equal length of $1 \mathrm{~m}$. The effects of gap size, channel width and liquid viscosity were carried out on the flow pattern transitions. They found map of the flow patterns of working fluids due to test conditions. In addition, they concluded that experimental results could only be used for used working fluids. However, the results would help to understand the boiling behaviour in minichannels. In the experimental study of Owhaib et al. [107], the effect of the mass flow and pressure on annular upward flow in the dryout region of a single circular vertical tube with a diameter of $1.33 \mathrm{~mm}$ was investigated. With the use of high speed CCD camera the behaviour of the two-phase flow, the liquid film dryout and the resulting transition to mist flow was visualized successfully. The authors concluded that dryout heat flux increased with increasing mass flux and with decreasing pressure. At low mass flux $\left(47.7 \mathrm{~kg} \mathrm{~m}^{-2} \mathrm{~s}^{-1}\right)$ the liquid front fluctuated and at the location where the wall temperature started to increase (vapour fraction was 0.73). However at high mass flux (124.4 $\mathrm{kg} \mathrm{m}^{-2} \mathrm{~s}^{-1}$ ) the liquid front was less fluctuating (vapour quality was 0.58 ). The results demonstrated that the heat transfer is low at vapour qualities above (about 0.6 for minichannel heat exchanger like evaporators). Yen et al. [108] studied the effect of geometrical shapes, which were square and circular, on the local heat transfer coefficient with similar hydraulic diameters. In the experimental study, HCFC123 was used as the working fluid. A high-speed camera was used to visualize the flow field inside both tubes. In this study, it was concluded that the local heat transfer coefficient $h$, versus vapour quality for different shaped cross-section at the same test condition ( $q$ and $\mathrm{m}^{\circ}$ constants). The heat transfer coefficient of the square tube was better than the circular one at low vapour quality range 0-0.4 where the nucleate boiling was dominant. With the increase in the vapour quality, the heat transfer coefficient of both tubes became close to each other at range of 0.4-1. Nevertheless, the heat transfer coefficient of square cross section tube was slightly better again. Since the corners of the square tube acted as active nucleation cavities, leading to the higher local heat transfer coefficient. However, the heat transfer coefficient of the circular tube remained at lower values at lower vapour quality due to the lack of cavities. Cheng et al. [109] proposed a new flow boiling heat transfer model and a new flow pattern map. The model and map were based on the flow boiling heat transfer mechanisms. In the experiments, the horizontal tubes were used and as the working fluid $\mathrm{CO}_{2}$ was used. In the beginning; due to the impacts which came from the reduced pressure and heat flux at low vapour qualities, a nucleate boiling heat transfer correlation was proposed. This correlation was for $\mathrm{CO}_{2}$. Then, a new correlation that was a nucleate boiling factor of heat transfer suppression related to the liquid film thickness and tube diameters was proposed. In this proposal, the basic approach was based on the flow boiling heat transfer mechanisms. In the developed flow pattern map, the changes in the flow boiling heat transfer trends were the basic of main scope, which related to the intermittent flow to annular flow transition criterion and annular flow to dry out region transition criterion. The usage of the flow boiling heat transfer model and the flow pattern map has a wide range of cases. The conditions, which were stated, are the tube diameters from 0.8 to $10 \mathrm{~mm}$, mass velocities from 170 to $570 \mathrm{~kg} \mathrm{~m}^{-2} \mathrm{~s}^{-1}$, heat fluxes from 5 to $32 \mathrm{~kW} \mathrm{~m}^{-2}$ and saturation temperatures from -28 to 25 ${ }^{\circ} \mathrm{C}$. Pamitran et al. [110] did experiments in order to define the flow pattern in the horizontal minichannel, which was using R410A. The test section was manufactured with stainless tubes. For experiments, inner diameters were 1.5 and $3.0 \mathrm{~mm}$, as well as, the lengths of test section was 1500 and $3000 \mathrm{~mm}$. Mass fluxes ranged from 300 to $600 \mathrm{~kg} \mathrm{~m}^{-2} \mathrm{~s}^{-1}$, when heat fluxes varied from 10 to $30 \mathrm{~kW} \mathrm{~m}^{-2}$. They mapped the experimental results with two different two-phase flow patterns prediction methods, which are present in the literature. They also developed a correlation, which was based on the superposition model for R410A, to determine heat transfer coefficients. Saisorn et al. [111] conducted experiments on horizontally located single steel tube of diameter $1.75 \mathrm{~mm}$ and 600 $\mathrm{mm}$ long for presenting heat transfer characteristics of different flow types and worked with R134a. The study started with determining the flow type (slug flow, throat-annular flow, churn flow, annular flow and annular-rivulet 
flow) and continued with the influence of heat flux, mass flux, vapour quality and saturation pressure on heat transfer coefficient. Results of the study indicated that heat transfer coefficient is directly proportional with the heat flux; on the contrary, unrelated with the mass flux and vapour quality. Ozawa et al. [112] experimentally investigated induced flow boiling in horizontal minichannel having diameter of 0.51 to $3.0 \mathrm{~mm}$ and they used $\mathrm{CO}_{2}$ as working fluid. Because the density differential between liquid and gas phase at high pressure $\mathrm{CO}_{2}$ is small and low surface tension, they studied in higher-pressure zone unlike others. Flow model, pressure loss, flow instability, boiling heat transfer, critical heat flux and intermittent dryout were investigated. It was seen that the impact of pressure on the flow mode was important in the slug-annular flow happening in transition region. Flow model transition principles, which were suggested earlier, were inadequate and a new method was suggested depending on the pattern dynamics. Dall'Olio and Marengo [113] investigated flow boiling of R134a and developed a new approach for investigation of R134a in flow boiling regime. In the study, they used mini and microchannel having hydraulic diameter of $4 \mathrm{~mm}$ and length of $320 \mathrm{~mm}$ and coating with several transparent conductive layers of Indium Tin Oxide (ITO). In addition, bubble geometrical detail that has been taken collected. It was seen that mass flux had no serious effect on flow model changes along the tubes. They classified the flow pattern in terms of statistical view; they were able to work on transition line and to expand them to the transition zone. They observed that coalescence had serious impact on the change of bubbles geometry in the tube and imaged the flow along the channel. Harirchian and Garimella [114] developed models in order to predict heat transfer coefficient of slug flow and annular/wispy-annular flow regimes in microchannel flow boiling. For slug flow regime, they modified the three-zone model of Thome et al. [67] and improved the prediction of heat transfer coefficient's performance of it with mean average error of $17.8 \%$. An analytical model was proposed for confined annular flow having MAE of $17.3 \%$ and annular/wispy-annular flow having MAE of $21.8 \%$. In addition, they estimated the pressure loss by using developed annular flow model for confined annular, annular or wispy-annular flow regimes conditions. For bubbly flow, the usage of homogenous model was suggested for the prediction of pressure loss. The study detected that flow boiling heat transfer and pressure loss can be predicted by means of flow regime based models. CostaPatry and Thome [115] presented a new flow pattern-based prediction method for determination of heat transfer coefficient by using experimental data. This experimental data includes four different refrigerants, various mass fluxes $\left(100-1100 \mathrm{~kg} \mathrm{~m}^{-2} \mathrm{~s}^{-1}\right)$, various heat fluxes $\left(8-260 \mathrm{~kW} \mathrm{~m}^{-2}\right)$ and various hydraulic diameters $(0.146-3.04$ $\mathrm{mm}$ ). They merged three-zone and annular flow models in order to produce a new flow pattern transition criterion for flow boiling conditions and developed a correlation for prediction of heat transfer coefficient. They compared the method with other researchers' experimental results and concluded that the method can predict the results in the range of $\pm 20 \%$. Magnini et al. [116] numerically analysed heat transfer and hydrodynamics of elongated bubbles in circular microchannel having $0.5 \mathrm{~mm}$ diameter. They investigated the influence of fluid properties on bubble growth rate and bubble terminal shapes for fixed Capillary numbers and different Reynolds numbers. It was observed that the bubble nose become sharpened with the rise of Reynolds number for fixed Capillary number. The change of bubble growth rate and the bubble nose velocity with time was also researched. Moreover, they compared the results of simulated and theoretical bubble nose positions, which are obtained for different operating conditions, and good agreement between the results was seen. In the study, the variation of the heat transfer coefficient with time was also investigated by using simulated data, transient heat conduction model with constant film thickness and steady heat conduction model with actual time-varying liquid film thickness. Piasecka [117] presented an experimental study in order to research heat transfer mechanism, flow patterns and pressure drop of FC72 flowing in minichannels. In the study, minichannels with enhanced heating surfaces (micro-recesses and mini-recesses distributed) were used and the two-dimensional temperature distribution was measured by means of liquid crystal thermography. The dependence of vapour quality and void fraction through the minichannel was investigated for different cross sections. Moreover, the researcher produced flow pattern map for both horizontal and vertical minichannels by means of the superficial liquid and vapour velocities. The researcher also obtained flow structure images for horizontally and vertically orientated minichannels with enhanced heating surfaces. Borhani and Thome [118] visualized the dryout and dry patch formation phenomenon of the R245fa in a multiport microchannel heat exchanger. Authors introduced an in-depth presentation of the wetting and rewetting processes with liquid film decomposition due to shear stress induced by vapour flow in the annulus. It was observed that the stresses and distortions caused by the droplet-vapour surface were not adequate to disintegrate the liquid film and heat exchanger inlet geometry having remarkable effects on the interfacial waves. It was also noted that these waves are strongly dependent on the operating conditions and thermophysical properties of the fluid. Charnay et 
al. [119] generated boiling flow pattern maps for R245fa in a minichannel with high saturation temperatures generally encountered in organic Rankine cycles. The authors presented a broad review of the viewpoints on macro-micro scale transition introduced by different researchers. Experiments revealed that the mass flow increase changes the trend of the flow to the annular type. At high saturation temperatures, stratified flow characteristics are observed while no stratification is occurred at lower temperatures. This phenomenon can be explained because of the reduced surface tension due to increase temperature and consider as a direct consequence of the gravity force's dominance over surface tension at high temperatures. Dryout of the flow was also investigated and the threshold of dryout found to decrease with an increase of the saturation temperature. Tibiriçá and Ribatski [120] performed experiments with R134a and R245fa to visualize the flow types and bubble formation processes in nucleate boiling under different operating conditions. Authors identified the onset of boiling and different flow patterns except stratified flow through high-speed camera recordings and presented flow pattern maps for used refrigerants. A modified version of $\mathrm{Fu}$ et al.'s correlation is generated to predict the bubble breakaway diameter. Authors also correlated bubble frequency and flow velocities of different phases in microchannel. A constant speed velocity zone for bubble is observed through experiments, which lead to the conclusion that the velocity of the fluid enclosing the bubble should be higher than the bubble velocity. Therefore, authors suggested that the drift velocity used in drift flux model and homogenous model should be negative and others should be zero in corresponding models respectively.

The boiling flow patterns in mini and microchannel were defined as the confined bubble, slug flow, and annular flow related mostly with the bubbles' length. Depending on the prevailing flow patterns in mini and microchannel, steady slug annular flow models are suggested to determine the characteristics of pressure drop and heat transfer. By way of a correlation procedure, the homogeneous flow models benefitting from empirical correlations are implemented to the boiling flow in mini and microchannel. Moreover, it is possible to state that the use of mini and microchannel are influential way to release heat from the heat sources.

\section{Flow Instabilities in Minichannels and Microchannel}

One of latest trends after 2006 is to study flow instabilities in mini or microchannel in the literature. Once two-phase flow phase alteration that happens in a small diameter channel in comparison to the capillary length, flow-boiling instabilities possibly will occur. The instabilities may be considered as static or dynamic; however, their intensity is higher in microchannel as they are valid for classical-sized channels caused by the larger amount of volume output of vapour that causes significant pressure drop. Static ones cause a new steady-state point instead of the equilibrium point. They include Ledinegg instability, boiling crisis, bumping, geysering or chugging because of the fact that they are evaluated with stationary models merely. Dynamic ones occur by the system's inertia, it should be noted that the state of stationary is insufficient to determine the destabilization threshold of the instabilities of acoustic waves, pressure drop oscillations or thermal oscillations. The works on this subject are summarized chronologically in the following paragraphs.

Brutin et al. [121] performed experiments to investigate the heat and mass transfer and examine twophase flow instabilities in rectangular microchannel with hydraulic diameter of $889 \mu \mathrm{m}$. According to the experimental set-up, two kinds of behaviour were observed. One of the behaviours was a steady state characterized by pressure drop fluctuations with low amplitudes $\left(0.5\right.$ to $\left.5 \mathrm{kPa} \mathrm{m}^{-1}\right)$. The other was a non-stationary state of twophase. In addition, the steady and unsteady thermo-hydraulic behaviours related to heat flux and mass velocity were analysed. It was also noted by the authors that two characteristic bubbles, small and huge, were formed in the experiments. Berglers and Kandlikar [122] studied on the nature and mechanism of critical heat flux in microchannel. Critical heat flux is the upper limit of heat flux. Major issues, which related with the use of microchannel, were examined. This study focused on bulk boiling heat transfer, which exists in microelectronic heat sink by high heat loads. This study showed that there are two kinds of instability. The first one is upstream compressible volume instability and the other one is the Ledinegg instability. Thus, the critical condition is the result of one of them. Consequently, if the channel flow were kept stable by an inlet restriction at the inlet of the each channel, the values of CHF can be lower than the expected values. Two kinds of instability can be eliminated by appropriate inlet restriction. Kandlikar [123] studied the nucleation during the flow boiling in microchannel. Therefore, the literature on onset of nucleate boiling was reviewed and the relationships between the local bulk subcooling and local wall superheat presented as a function of nucleation cavity diameters. The place of a nucleation for local wall superheat and liquid subcooling were also taken. The flow characteristics such as flow 
boiling, heat transfer rates and critical heat flux in microchannel and minichannels were analysed. With the use of a high speed camera, the effects of them on flow boiling stability were studied experimentally. An article presented by Kandlikar [124] related two major issues, one is heat transfer mechanisms and the second one is related to flow stabilization. He emphasized the importance of the flow boiling and flow patterns in microchannel and minichannels because of direct effects on heat transfer rate. The experimental data obtained with the high speed imaging and numerical simulation showed that a growing vapour bubble in the superheated liquid verify the high growth rates at liquid-vapour interface, compelling the liquid flow in reverse direction. An effective method with the regard of nucleation sites and restriction inlet flow was introduced to reduce the instabilities. The author stated that the information given in this study provides insight into the flow boiling mechanisms and guidance for future work. Qi et al. [125] studied the flow boiling in micro-tubes with four different diameters $0.531,0.834,1.041$ and $1.931 \mathrm{~mm}$ in two parts. The first part that was focused on the onset of nucleate boiling (ONB) two phase flow instability and two-phase flow pressure drop. The fluid used in this study was liquid nitrogen unlike most studies in the literature because of smaller viscosity, higher thermal conductivity, smaller density ratio of liquid phase to vapour phase, comparing the refrigerants and water. It was clearly seen that an intensive experimental study carried out to investigate the effects of pressure drop, mass flux, wall temperatures, heat flux change compared to the predicted results by the modified Thome model at ONB point. A physical model is proposed to explain the ONB oscillations and block phenomenon. Wang et al. [126] experimentally investigated the effects of three different inlets/outlets on flow characteristics of degassed water boiling in microchannel. Authors reported that the restricted inlet/free outlet structure has the most stable flow characteristics. However, due to the restrictors at the inlet, this configuration also showed highest-pressure drop. In the no inlet restrictor setups, fluctuations in pressure are observed at certain times in bubble growth process. Heat transfer coefficient is found to be dependent on the heat flux in low quality regions while this dependency fades away at higher vapour quality values. Vapour quality also was found to influence the heat transfer coefficient on subcooled region. Lee et al. [127] carried out experiments on 48 parallel ducts of $353 \mu \mathrm{m}$ hydraulic diameter and used water as a working fluid in order to see the fluctuation effects. Experiments were conducted on varying heat flux; inlet supercooling and mass fluxes and their instability parameter were obtained. In order to prevent bubble formation, which led instability for the flow and fluctuations, locating an orifice at the inlet or a divergent channel at the outlet of the duct was recommended. Kandlikar's instability model was expanded by taking into account those modifications and a new term called instability parameter was derived. Lee and Yao [128] established an experimental set in order to reduce the instability in twophase microchannel flows by using a liquid tank to regulate the flow and a heater located before the ducts. Moreover, they constituted a model to determine the instability of the parallel duct evaporator system and validated it with the tests. They observed that unsteadiness occurs during two-phase flows in parallel ducts. Finally, they showed that instability of the system could be prevented by simple modifications for microchannel flows. A recent solution method to improve the uniformity of the liquid distribution and reducing backflow in the inlet header of a microchannel evaporator, in an air conditioning unit using R134a was developed by Tuo and Hrnjak [129]. Authors proposed opening of two venting points on the each end of the inlet manifold, which release the backflow vapour to a gas separator. It can be clearly observed that the manifold with the venting scheme (FGBR) had more uniform surface temperature profile. It was observed that the backflow and temperature deviations at the inlet occur in an oscillatory manner and small amount of liquid also backflow through the channels. Inlet flow visualization and temperature distribution in the evaporator reveal that the application of the venting ports inhibits the backflow and improves equal flow distribution over the evaporator channels. Pressure drop measured in the evaporator also decreased due to the implementation of the venting ports. Tuo and Hrnjak [130] focused on the visualization and effects which affect the reverse flow on the microchannel evaporator in an air conditioning unit also using R134a as refrigerant. Fluctuations observed in pressure drop were found to be connected with the succession of the flow type in the inlet section of the evaporator and the inception of the reverse flow occurred at the end of this section. It was also found that the boiling instabilities have high influence over the reverse flow and the reverse flow may inhibit the nucleation of bubbles and resulted in annular flow inside the channel. Wang et al. [131] investigated the flow instabilities and fluctuations in boiling with three different sized microchannel using FC72. Experiments indicated that the high amplitude fluctuations is due to the reasons of the mechanics in two phase flow since no fluctuation is observed in single phase flow conditions. Reverse flow is found to be the source of the low frequency high amplitude fluctuations. Authors reported that the mass flux is the dominant factor in pressure drop and pressure oscillations and increased mass flux results in reduced backward expansion of vapour 
in channels, which prevents reverse flow. Higher heat flux also was found to increase the pressure drop however mass flux's dominance over heat flux is proved after further analysis. Although different channel sizes show some differences over the entire working conditions, their effects are found to be more distinctive at higher mass flow rates. Surface temperature of the channel is also affected from the fluctuations in the flow and the authors concluded that the special monitoring would be required at high heat flux conditions due to dry out which results in damage to the surface. Edel and Mukherjee [132] investigated the effect of using alumina nanoparticles in water flowing in single-microchannel evaporator. Deposition of nanoparticles at the microchannel wall increased the bubble growth rate and slowed the bubble elongation speed. Increased number of nucleation sites due to deposition also decreased the flow instability and dryout duration. Authors therefore concluded that the use of nanoparticles in micro heat exchangers would be a beneficial practice due to their positive contribution to flow stability.

Researchers on flow boiling instabilities in mini and microchannel have given a large number of knowledge recently. According to the most investigations in the literature, instability phenomena occurring in mini and microchannel has similar characteristics with those in classical channels. The stability transition criteria including the oscillation frequency of the instabilities have been proved by scaling laws. By means of this information, space confinement is considered as an origin for all flow-boiling instabilities in mini and microchannel. On the other hand, other supplementary instabilities may be caused by coupling with the experimental loop or an injection device. New experimental works on smaller hydraulic diameters should be done to study the subject at the scale of a bubble. Conventional flow boiling phenomena is different from some confinements having bubble sizes near to or larger than the hydraulic diameter. The study of flow boiling in compact heat exchangers working in microgravity is also a promising subject for the industry.

\section{Surface Modification in Minichannels and Microchannel}

Two-phase mini and microchannel heat source have been shown up recently as a leading way out for thermal managing of related applications. This idea brought many advantages such as large thermal capacity and low thermal resistance between the heat source and the cooler. Additionally, boiling flows demand a smaller amount of coolant flow rate and pumping power to remove a heat load compared to single-phase flows. Thus, mini and microchannel cooling devices can enable enhancements in temperatures' uniformity, and take up a little volume possibly. Numerous theoretical, numerical and experimental works have been performed for boiling flow in conventional size channels. Industrial applications have microscale-boiling processes, and the developed models and correlations regarding with conventional channels should be clarified for their applicability to mini and microchannel. Moreover, there is no clear agreement in open sources on the conversion of macroscale conditions to microscale ones during boiling flows.

Koşar et al. [133] performed boiling heat transfer experiments in flow. They used the microchannel for flow with re-entrant cavities. The average two-phase heat transfer coefficient and CHF conditions had been procured. This was over range of effective heat fluxes and mass velocities, which were $28-445 \mathrm{~W} \mathrm{~cm}^{-2}$ for heat fluxes and 41-302 $\mathrm{kg} \mathrm{m}^{-2} \mathrm{~s}^{-1}$ for mass velocities. With the different mass flux and exit qualities, the trends for CHF have been examined. According to the results, it seemed that a transition between nucleate and convective boiling was obvious. This case was evaluated in terms of the Reynolds and the Boiling numbers. For low Re an Bo, the nucleate boiling was dominant. The purpose was recognizing two regions with convective and nucleate boiling dominance. The corresponding flow map was researched. Another result of experiments showed that heat transfer coefficients demonstrated trends similar to predictions of nucleate dominant correlations, which related to minichannels. Sitar et al. [134] investigated boiling characteristics of water and FC72 in microchannel with inside etched surfaces. Etches are made in four different geometrical shapes and proposed etchings proved to have lower temperatures for the onset of boiling. High superheat temperatures needed for onset of boiling are found to be related to the small flow area of the microchannel. This phenomenon resulted in eruptive boiling of FC72. By comparison, of etched and smooth channel surfaces with different channel geometries, both of the properties as well as fluid type were found to have an influence over boiling incipience temperature. Karayiannis et al. [135] intended to clarify disagreement about the parameter effecting flow boiling heat transfer coefficient. For this purpose, they investigated the influence of the heated length $(150-450 \mathrm{~mm})$ and surface characteristics on flow boiling heat transfer. They used seamless cold drawn and welded tubes as test sections and concluded that the tubes having different surface properties performed quite different flow boiling characteristics. They also observed that the tube having shorter heated length had higher heat transfer coefficient compared to longer ones for the same exit quality. 
Moreover, the effects of vapour quality and heat flux on heat transfer coefficient were studied for various heated lengths. It was seen that the heat transfer coefficient increased with increasing heat flux and had slight changes with vapour quality for shorter tube. As another result of the study, they stated that change in the heated length and inner surface properties were the main reason of conflict between the researchers' experimental results. Lee et al. [136] numerically compared the heat transfer performance of smooth and finned microchannel by using sharpinterface LSM (Level Set Method). They studied the influence of fin length, spacing and height on flow boiling in a micro channel. Temperature field and bubble growth of smooth and finned microchannel were plotted for unsteady conditions. In finned micro channel, bubble growth occurred quicker than smooth one. They also sighted that larger fin spacing enhanced boiling heat transfer in finned microchannel. Since the contact area of liquidvapour interface increased with the usage of finned micro channel, the boiling heat transfer augmented up to $33 \%$ based on total fin surface area. Zhou et al. [137] carried out a numerical investigation of a microchannel with internal cavities to determine the optimal cavity geometry by using LSM. Applied model used uniform heat flux model and regular distributed cavities over the surface. Microchannel with cavity structure found to have lower wall temperatures and higher bubble generation rate, which qualified its performance as dominant over plain surface microchannel. Further investigation of cavity geometry revealed that the optimum cavity mouth, diameter and height should be 9.5, 120 and $60 \mu \mathrm{m}$ respectively to minimize the wall superheat temperature. Augmentation of cavity density found to have an increasing effect on critical heat flux on regular cavity distribution configuration while contrary results have been found with random distribution. Non-uniform heat flux conditions also investigated and found to inhibit cooling capacity resulted in higher wall temperatures. Piasecka [138] investigated flow boiling of FC72 in a rectangular minichannel with enhanced heater surface by means of liquid crystal thermography. Cavities formed on the heater surface lowered the heat flux necessary for the onset of boiling, however, they are found to be ineffective on the position of the boiling front occurred in the minichannel. Also the bubble form is dominant at the onset of boiling and early stage of growth when applied heat flux is increased similar to the observations in smooth heater surface conditions. Author also used homogeneous and separated flow models to predict the pressure drop data in the study and reported that the both models have an agreeable performance with the data. Pike-Wilson and Karayiannis [139] used copper, brass and stainless steel minichannel tubes for investigation of surface profile on the boiling and pressure drop of R245fa. A broad explanation on definition of surface roughness and different aspects of the tube materials' surface profiles were presented by authors. For all tube materials, flow type was mainly the annular flow except the flow regime at the low heat fluxes nevertheless stainless steel tube maintained annular flow even at these region. Although brass tube showed the higher-pressure drop, there was no apparent correlation between the surface roughness and the pressure drop. In addition, distribution of two-phase pressure drop elements regarding acceleration, frictional and gravitational have no distinct variety with different tube materials. None of the correlations collected from the literature for the determination of pressure drop showed appropriate results, which were due to the non-applicability of the correlations to R245fa. Authors also investigated the influence of the inlet pressure on the pressure drop and stainless steel found to have the most distinct deviation in pressure drop. Investigation of heat transfer showed that the surface profile have prominent effect on the heat transfer since the observed diversity between the results obtained from the same tube material at different locations. They also lead to the conclusion that the differences between the tubes may not due to the different conductivities only. Yang et al. [140] conducted experiments to investigate the effect of nano surface enhancements applied to microchannel surface on the boiling heat transfer of deionized water. Plain and enhanced surfaces generated by means of electrolysis electrochemical etching technique that were compared were investigated to deduce the differences of the enhanced surface microchannel. Enhanced surface was consisted of applied Si nanowires to the inside surface of the microchannel. A new flowboiling regime named single annular flow by the authors who was observed was characterized in Si nanowire applied microchannel. Enhanced surfaced microchannel also performed superior in terms of highest working heat flux and a maximum enhancement of $32.6 \%$ in heat transfer to the plain microchannel was observed in Si nanowire channels. Authors also confirmed that the application of nano surface increase bubble departure frequency and decrease bubble departure diameter due to increased wettability and cavity size. In their subsequent work, Yang et al. [141] further investigated the single annular flow regime occurring in Si nanowire channels and its effects on pressure drop and heat transfer. Pressure drop in Si nanowire channel is about $48 \%$ lower than the smooth microchannel, which are believed to be the reason of the single annular flow as reported according to the study. Although no complete explanation between this flow regime and lower pressure drop is associated, it is concluded 
that this phenomenon is a result of the separation of phases and lack of existence of different flow regimes. Nonexistence of different flow patterns is also concluded to the higher critical heat flux values observed in Si nanowire microchannel since liquid distribution over the microchannel was improved by the capillary flows and dry-out was delayed. Another numerical simulation performed by Lee and Son [142] investigated the effects of enhanced surface geometries to the heat transfer in microchannel by applying sharp-interface level-set method. Authors modelled longitudinal and transverse fins inside the inner surface of the channel and computed the augmentation acquired in boiling heat transfer. Their results showed that relatively shorter time is required for a bubble to grow with transverse fins. However, further analyses revealed the effectiveness of using longitudinal fins at the same fin height for improvement of the heat transfer rate. Piasecka [143] investigated heat transfer in pool and flow boiling of FC72 in a minichannel with enhanced surfaces. Surface modifications are applied by spark erosion technique. Experiments were carried out approximately at the atmospheric pressure. Pool boiling heat transfer coefficients resulted higher values than flow boiling case. The existence of mini and microchannel for boiling applications have significance in recent years due to its high capacity for transferring the heat fluxes especially in the mini and micro electronic devices in space, communication, biology and industry. Some of these devices are air bag acceleration sensors, micro endoscopes, micro heat exchangers, micro heat pump systems, micro valves, and micro cold plates. In these devices, phase change process occurs and dominates the phenomena, which is very complex for theoretical and numerical solutions especially. Unfortunately, the majority of the works are away from the generalization of the models and correlations, they have focused on specific fluids and geometries of heat exchangers. The restrained thought of each parameter affecting the boiling process in these devices should be investigated methodically. The problematic issues are stated as entrance, exit effects, quality effects and change in channel erosion mainly in open sources including contradictions in measurements. Extra information on two-phase flow in a single microchannel (air-water) [144-151], two-phase flow of refrigerant in multiport minichannel [44, 152-156], two-phase flow of refrigerant in short tube orifice [157-164], two-phase flow in a single microchannel (refrigerant) [165-168], micro channel heat sink with nanofluids [169-170], and general reviews on microchannel can be seen from authors previous studies [171-175], respectively.

\section{CONCLUSION}

Studies involving flow boiling in mini and microchannel geometries were gathered together and their brief summaries were presented tables in this review. Following comments were derived from the investigated studies from literature as respectively.

Flow boiling in mini or microchannel structures is expected to have more application in the industry in near future due to their cooling ability in extreme small components. There are still major drawbacks and issues regarding their usability, mostly due to inadequate data and theory that represents the phenomenon, high pressure drops associated with small geometries and non-uniform fluid distribution in heat exchanger manifolds. Definition of micro and minichannels is still a problematic issue regarding its classification based on hydraulic diameter. There is no consensus among researchers, who have observed the flow regimes, on the sequence of flow regime stages. Elongated bubble flow regime, followed by annular flow, is considered as the most significant one in comparison to the nucleate boiling due to the existence of thin liquid film around bubbles.

Heat flux and saturation temperature are found to be dominant in comparison to the others on the heat transfer coefficient. On the other hand, mass velocity and vapour quality have been reported as the most effective parameters on the nucleate boiling. The models, developed for macrochannels or conventional tubes, could not reflect the characteristics of micro and minichannels accurately especially regarding with the specific vapour quality ranges because nucleate boiling regime and turbulent effects are not the affective mechanisms in these narrow channels. There is an inconsistent situation on the effect of oil in the evaporator regarding its influence on the heat transfer coefficient on the contrary to the situation of concurrence on the increase in pressure drop. There is still lack of pure theoretical models for the prediction of local values in small-scale channels. Pure theoretical criteria can be defined as two main sections as follows; the degree of development of the calculations in a particular method (for example, the number of channels in multichannel methods) and the degree of specific accuracy of the method. The lack of adequate experimental data introduces the necessity to evaluate the accuracy of cross-sectional data on pure theoretical criteria. When applying these criteria to the data listed in the tables, they are only considered as the energy ranges corresponding to the validity area of the corresponding method used in the calculations. 
There is not enough number of studies regarding with the numerical solution of flow boiling for the use of refrigerants especially due to the hardness of preparation of UDF code with a CFD software. There is still some gap on the use of mixtures for the flow boiling process in small-scale channels regarding a model having a detailed study of the mechanisms of mass, momentum and heat transfer. Heat transfer in liquid-liquid slug flows in smallscale channels needs to be studied in detail due to the insufficient number of studies. Experimental works should be done having similar operating conditions systematically by researchers to avoid from the inconsistency among their database. The use of nanoparticles in microchannel heat exchangers will be a beneficial practice due to their positive contribution to flow stability. The use of nanoparticles in two-phase flows, defined as nano refrigerants especially, is still under consideration in the literature. Generalization of the developed models are still necessary for researchers to predict the heat transfer and pressure drop characteristics practically. There is no single general theoretical model or empirical correlation to predict the phenomena in macro/micro/nano scaled tubes and channels. In the last 15 years, the number of flow boiling studies in micro and minichannels have more and more increased importantly and the interest to study on the flows in narrow channels is expected to be extended to the nanochannels in the near future. For that reason, revision on the existing models will be needed definitely.

\section{ACKNOWLEDGEMENT}

All authors would like to thank the Department of Mechanical Engineering, King Mongkut's University of Technology Thonburi for the support during this research in Thailand. The authors would like to thank the "Research Chair Grant" National Science and Technology Development Agency, the Thailand Research Fund and the National Research University Project for the support.

\section{NOMENCLATURE}

Bo Boiling number

$\mathrm{Ca}_{1} \quad$ Liquid capillary number

CCD Charge coupled device

CHF Critical heat flux, $\mathrm{W} \mathrm{m}^{-2}$

Co Confinement number

CPU Central processing unit

$\mathrm{d}_{\text {bubble }} \quad$ Bubble diameter, $\mathrm{m}$

$\mathrm{d}_{\mathrm{h}} \quad$ Hydraulic diameter, $\mathrm{m}$

$d_{\text {he }} \quad$ Heated equivalent diameter, $m$

$\mathrm{d}_{\mathrm{i}} \quad$ Inner diameter, $\mathrm{m}$

EDL Electric double layer

F Reynolds number factor

FGB Flash gas bypass

FGBR Revised flash gas bypass

$\mathrm{G} \quad$ Mass velocity, $\mathrm{kg} \mathrm{m}^{-2} \mathrm{~s}^{-1}$

h Heat transfer coefficient, $\mathrm{W} \mathrm{m}^{-2} \mathrm{~K}^{-1}$

ID Inner diameter, $\mathrm{m}$

ITO Indium tin oxide

$\mathrm{K}_{\mathrm{p}} \quad$ Pressure dimensionless parameter

$\mathrm{L}_{\mathrm{h}} \quad$ Heated length, $\mathrm{m}$

LSM Level set method

$\dot{\mathrm{m}} \quad$ Mass flux, $\mathrm{kg} \mathrm{s}^{-1}$

MAE Mean absolute error

NEMD Non-equilibrium molecular dynamics

$\mathrm{Nu} \quad$ Nusselt number

OD Outer diameter, $m$

ONB Onset of nucleate boiling

$\mathrm{P} \quad$ Pressure, $\mathrm{Pa}$

ppm Parts per million

q Heat flux, $\mathrm{W} \mathrm{m}^{-2}$ 


$\begin{array}{ll}\mathrm{Re}_{\mathrm{g}} & \text { Reynolds number } \\ \mathrm{Re}_{\mathrm{g}} & \text { Gas Reynolds number } \\ \mathrm{Re}_{\mathrm{l}} & \text { Liquid Reynolds number } \\ \mathrm{Re}_{\mathrm{LF}} & \text { Film Reynolds number } \\ \mathrm{S} & \text { Suppression factor } \\ \mathrm{SEM} & \text { Scanning electron microscope } \\ \mathrm{SFSM} & \text { Sequential function specification method } \\ \mathrm{SOI} & \text { Silicon on insulator } \\ \mathrm{T} & \text { Temperature, }{ }^{\circ} \mathrm{C} \\ \mathrm{We} & \text { Weber number } \\ \mathrm{We} & \text { Mean Weber number } \\ \mathrm{W}_{\mathrm{i}} & \text { Channel inner width, m } \\ \text { wt. } & \text { Weight } \\ \mathrm{X} & \text { Lockhart-Martinelli parameter } \\ \mathrm{x} & \text { Quality }\end{array}$

\section{REFERENCES}

[1] Thome, J. R., Boiling In Microchannels: A Review of Experiment And Theory, International Journal of Heat and Fluid Flow, vol. 25, no. 2, 128-139, 2004.

[2] Cheng, L., and Mewes, D., Review of Two-Phase Flow And Flow Boiling of Mixtures In Small And Minichannels, International Journal of Multiphase Flow, vol. 32, no. 2, 183-207, 2006.

[3] Baldassari, C., and Marengo, M., Flow Boiling In Microchannels And Microgravity, Progress in Energy and Combustion Science, vol. 39, no. 1, pp. 1-36, 2013.

[4] Tibiriçá, C. B., and Ribatski, G., Flow Boiling In Micro-Scale Channels-Synthesized Literature Review, International Journal of Refrigeration, vol. 36, no. 2, pp. 301-324, 2013.

[5] Kandlikar, S. G., Fundamental Issues Related To Flow Boiling In Minichannels And Microchannels, Experimental Thermal and Fluid Science, vol. 26, no. 2, pp. 389-407, 2002.

[6] Lin, S., Sefiane, K., and Christy, J. R. E., Prospects of Confined Flow Boiling In Thermal Management of Microsystems, Applied Thermal Engineering, vol. 22, no. 7, pp. 825-837, 2002.

[7] Wu, Z., and Sundén, B., On Further Enhancement of Single-Phase And Flow Boiling Heat Transfer In Micro/Minichannels, Renewable \& Sustainable Energy Reviewers, vol. 40, pp. 11-27. 2014.

[8] Kim, S, M., and Mudawar, I., Review of Databases And Predictive Methods For Heat Transfer In Condensing And Boiling Mini/Micro-Channel Flows, International Journal of Heat and Mass Transfer, vol. 77, pp. 627-652, 2014.

[9] Salman, B. H., Mohammed, H. A., Munisamy, K. M., and Kherbeet, A. S., Characteristics of Heat Transfer And Fluid Flow In Microtube And Microchannel Using Conventional Fluids And Nanofluids: A review, Renewable \& Sustainable Energy Reviewers, vol. 28, pp. 848-880, 2013.

[10] Kew, P. A., and Cornwell K., Correlations For The Prediction of Boiling Heat Transfer In Small-Diameter Channels, Applied Thermal Engineering, vol. 17, no. 8-10, pp. 705-715, 1997.

[11] Lee, H. J., and Lee, S. Y., Heat Transfer Correlation For Boiling Flows In Small Rectangular Horizontal Channels With Low Aspect Ratios, International Journal of Multiphase Flow, vol. 27, no. 12, pp. 2043-2062, 2001.

[12] Kandlikar, S. G., and Steinke, M. E., Predicting Heat Transfer During Flow Boiling In Minichannels And Microchannels, ASHRAE Transactions. vol. 109, pp. 667-676, 2003.

[13] Kandlikar, S. G., and Balasubramanian, P., An Extension of The Flow Boiling Correlation To Transition, Laminar, And Deep Laminar Flows In Minichannels And Microchannels, Heat Transfer Engineering, vol. 25, no. 3, pp. 86-93. 2004.

[14] Agostini, B., and Bontemps, A., Vertical Flow Boiling of Refrigerant R134a In Small Channels, International Journal of Heat and Fluid Flow, vol. 26, , no. 2, pp. 296-306, 2005.

[15] Yun, R., Kim, Y., and Kim, M. S., Flow Boiling Heat Transfer of Carbon Dioxide In Horizontal Mini Tubes, International Journal of Heat and Fluid Flow, vol. 26, , no. 5, pp. 801-809, 2005. 
[16] Jokar, A., Hosni, M. H., and Eckels, S. J., Dimensional Analysis On The Evaporation And Condensation of Refrigerant R-134a In Minichannel Plate Heat Exchangers, Applied Thermal Engineering, vol. 26, no. 17-18, pp. 2287-2300, 2006.

[17] Choi, K. Il., Pamitran, A. S., Oh, C. Y., and Oh, J. T., Boiling Heat Transfer of R-22, R-134a, And CO In Horizontal Smooth Minichannels, International Journal of Refrigeration, vol. 30, no. 8, pp. 1336-1346, 2007.

[18] Choi, K. Il., Pamitran, A. S., Oh, J. T., and Oh, H. K., Two-Phase Pressure Drop of R-410A In Horizontal Smooth Minichannels, International Journal of Refrigeration, vol. 31, , no. 1, pp. 119-129, 2008.

[19] Pamitran, A. S., Choi, K. Il., Oh, J. T., and Oh, H. K., Two-Phase Pressure Drop During $\mathrm{CO}_{2}$ Vaporization In Horizontal Smooth Minichannels, International Journal of Refrigeration, vol. 31, no.8, pp. 1375-1383, 2008.

[20] Bertsch, S. S., Groll, E. A., and Garimella, S. V., A Composite Heat Transfer Correlation For Saturated Flow Boiling In Small Channels, International Journal of Heat and Mass Transfer, vol. 52, no. 7-8, pp. 2110-2118, 2009.

[21] Choi, K. Il., Pamitran, A. S., Oh, J. T., and Saito, K., Pressure Drop And Heat Transfer During Two-Phase Flow Vaporization of Propane In Horizontal Smooth Minichannels, International Journal of Refrigeration, vol. 32, no. 5, pp. 837-845, 2009.

[22] Koşar, A., A Model To Predict Saturated Critical Heat Flux In Minichannels And Microchannels, International Journal of Thermal Sciences, vol. 48, no. 2, pp. 261-270, 2009.

[23] Sun, L., and Mishima, K., Evaluation Analysis of Prediction Methods For Two-Phase Flow Pressure Drop In Mini-Channels, International Journal of Multiphase Flow, vol. 35, no. 1, pp. 47-54. 2009.

[24] Sun, L., and Mishima, K., An Evaluation of Prediction Methods For Saturated Flow Boiling Heat Transfer In Mini-Channels, International Journal of Heat and Mass Transfer, vol. 52, no. 23-24, pp. 5323-5329, 2009.

[25] Boudouh, M., Gualous, H. L., and De Labachelerie, M., Local Convective Boiling Heat Transfer And Pressure Drop of Nanofluid In Narrow Rectangular Channels, Applied Thermal Engineering, vol. 30, , no. 17-18, pp. 2619-2631, 2010.

[26] Brix, W., Kærn, M. R., and Elmegaard, B., Modelling Distribution of Evaporating $\mathrm{CO}_{2}$ In Parallel Minichannels, International Journal of Refrigeration, vol. 33, , no. 6, pp. 1086-1094, 2010.

[27] Dutkowski, K., Influence of The Flashing Phenomenon On The Boiling Curve of Refrigerant R134a In Minichannels, International Journal of Heat and Mass Transfer, vol. 53, , no. 5, pp. 1036-1043, 2010.

[28] Dutkowski, K., Air-Water Two-Phase Frictional Pressure Drop In Minichannels, Heat Transfer Engineering, vol. 31, no. 4, pp. 321-330, 2010.

[29] Pamitran, A. S., Choi, K. I., Oh, J. T., and Hrnjak, P., Characteristics of Two-Phase Flow Pattern Transitions And Pressure Drop of Five Refrigerants In Horizontal Circular Small Tubes, International Journal of Refrigeration, vol. 33, no. 3, pp. 578-588, 2010.

[30] Ribeiro, G. B., Barbosa, J. R. and Prata, A. T., Mini-Channel Evaporator/Heat Pipe Assembly For A Chip Cooling Vapor Compression Refrigeration System, International Journal of Refrigeration, vol. 33, no. 7, pp. 14021412, 2010.

[31] Bang, K. H., Kim, K. K., Lee, S. K., and Lee, B.W., Pressure Effect On Flow Boiling Heat Transfer of Water In Minichannels, International Journal of Thermal Sciences, vol. 50, no. 3, pp. 280-286, 2011.

[32] Chen, C.A., Li, K. W., Lie, Y. M., and Lin, T. F., Saturated Flow Boiling Heat Transfer of R-410a And Associated Bubble Characteristics In A Narrow Annular Duct, International Journal of Heat and Mass Transfer, vol. 54, no. 23-24, pp. 4988-5000, 2011.

[33] Copetti, J. B., Macagnan, M. H., Zinani, F., and Kunsler, N. L. F., Flow Boiling Heat Transfer And Pressure Drop of R-134a In A Mini Tube: An Experimental Investigation, Experimental Thermal and Fluid Science, vol. 35, no. 4, pp. 636-644, 2011.

[34] Kaew-On, J., Sakamatapan, K., Wongwises, S., Flow Boiling Heat Transfer of R134a In The Multiport Minichannel Heat Exchangers, Experimental Thermal and Fluid Science, vol. 35, no. 2, pp. 364-374, 2011.

[35] Wu, J., Koettig, T., Franke, C., Helmer, D., Eisel, T., and Haug, F., et al., Investigation of Heat Transfer And Pressure Drop of $\mathrm{CO}_{2}$ Two-Phase Flow In A Horizontal Minichannel, International Journal of Heat and Mass Transfer, vol. 54, no. 9, pp. 2154-2162, 2011.

[36] Li, W., and Wu, Z., Generalized Adiabatic Pressure Drop Correlations In Evaporative Micro/MiniChannels, Experimental Thermal and Fluid Science, vol. 35, no. 6, pp. 866-872, 2011. 
[37] Oh, J. T., Pamitran, A. S., Choi, K.I., and Hrnjak, P., Experimental Investigation On Two-Phase Flow Boiling Heat Transfer of Five Refrigerants In Horizontal Small Tubes of 0.5, 1.5 And 3.0 Mm Inner Diameters, International Journal of Heat and Mass Transfer, vol. 54, no. 9-10, pp. 2080-2088, 2011.

[38] Ong, C.L., and Thome, J.R., Macro-To-Microchannel Transition In Two-Phase Flow: Part 2 - Flow Boiling Heat Transfer And Critical Heat Flux, Experimental Thermal and Fluid Science, vol. 35, no. 6, pp. 873$886,2011$.

[39] Saisorn, S., Kaew-On, J., and Wongwises, S., Two-Phase Flow of R-134a Refrigerant During Flow Boiling Through A Horizontal Circular Mini-Channel, Experimental Thermal and Fluid Science, vol. 35, no. 6, pp. 887-895, 2011.

[40] Piasecka, M., Maciejewska, B., The Study of Boiling Heat Transfer In Vertically And Horizontally Oriented Rectangular Minichannels And The Solution To The Inverse Heat Transfer Problem With The Use of The Beck Method And Trefftz Functions, Experimental Thermal and Fluid Science, vol. 38, pp. 19-32, 2012.

[41] Wu, Z., and Li, W., A New Predictive Tool For Saturated Critical Heat Flux In Micro/Mini-Channels: Effect of The Heated Length-To-Diameter Ratio, International Journal of Heat and Mass Transfer, vol. 54, no. 1314, pp. 2880-2889, 2011.

[42] Farahani, S. D., and Kowsary, F., Estimation Local Convective Boiling Heat Transfer Coefficient In Mini Channel, Internatational Communications in Heat and Mass Transfer, vol. 39, no. 2, pp. 304-310, 2012.

[43] Kaew-On, J., Sakamatapan, K., and Wongwises, S., Flow Boiling Pressure Drop of R134a In The Counter Flow Multiport Minichannel Heat Exchangers, Experimental Thermal and Fluid Science, vol. 36 ,pp. 107-117, 2012.

[44] Kaew-On, J., and Wongwises, S., New Proposed Two-Phase Multiplier And Evaporation Heat Transfer Coefficient Correlations For R134a Flowing At Low Mass Flux In A Multiport Minichannel, Internatational Communications in Heat and Mass Transfer, vol. 39, no. 6, pp. 853-860, 2012.

[45] Liu, Z., Bi, Q., Guo, Y., and Su, Q., Heat Transfer Characteristics During Subcooled Flow Boiling of A Kerosene Kind Hydrocarbon Fuel In A 1 mm Diameter Channel, International Journal of Heat and Mass Transfer, vol. 55, no. 19-20, pp. 87-4995, 2012.

[46] Maqbool, M. H., Palm, B., and Khodabandeh, R., Experimental Investigation of Dryout of Propane In Uniformly Heated Single Vertical Mini-Channels, Experimental Thermal and Fluid Science, vol. 37 , pp. 121-129, 2012 .

[47] Mortada, S., Zoughaib, A., Arzano-Daurelle, C., and Clodic, D., Boiling Heat Transfer And Pressure Drop of R-134a And R-1234yf In Minichannels For Low Mass Fluxes, International Journal of Refrigeration, vol. 35, no. 4, pp. 962-973, 2012.

[48] Anwar, Z., and Lahore, T., Evaporative Heat Transfer With R134a In A Vertical Minichannel, Pakistan Journal of Engineering And Applied Sciences, vol. 13, no. 9, pp. 101-109, 2013.

[49] Saisorn, S., Kaew-On J., and Wongwises, S., An Experimental Investigation of Flow Boiling Heat Transfer of R-134a In Horizontal And Vertical Mini-Channels, Experimental Thermal and Fluid Science, vol. 46, pp. 232$244,2013$.

[50] Copetti, J. B., MacAgnan, M. H. and Zinani, F., Experimental Study on R-600a Boiling in $2.6 \mathrm{~mm}$ Tube, International Journal of Refrigeration, vol. 36, no. 2, pp. 325-334, 2013.

[51] Maqbool, M. H., Palm, B., and Khodabandeh, R., Investigation of Two Phase Heat Transfer and Pressure Drop of Propane in a Vertical Circular Minichannel, Experimental Thermal and Fluid Science, vol. 46, pp. 120$130,2013$.

[52] Mikielewicz, D., Wajs, J., Gliński, M., and Zrooga, A. B. R. S., Experimental Investigation of Dryout of SES 36, R134a, R123 and Ethanol in Vertical Small Diameter Tubes, Experimental Thermal and Fluid Science, vol. 44, pp. 556-564, 2013.

[53] Balavignesh, S., Umesh, V., and Raja, B., Flow Boiling Heat Characteristics of n-Pentane in a MiniChannel, Procedia Engineering, vol. 64, pp. 1524-1532, 2013.

[54] Kim, D., and Jeong, S. Effect of Micro-grooves on the Two-Phase Pressure Drop of $\mathrm{CO}_{2}$ in a MiniChannel Tube, International Journal of Refrigeration, vol. 36, no. 8, pp. 2040-2047, 2013.

[55] Kim, S. M., and Mudawar, I., Universal Approach to Predicting Saturated Flow Boiling Heat Transfer in Mini/Micro-Channels - Part I. Dryout Incipience Quality, International Journal of Heat and Mass Transfer, vol. 64, pp. 1226-1238, 2013. 
[56] Kim, S. M., and Mudawar, I., Universal Approach to Predicting Saturated Flow Boiling Heat Transfer in Mini/Micro-Channels - Part II. Two-phase Heat Transfer Coefficient, International Journal of Heat and Mass Transfer, vol. 64, pp. 1239-1256, 2013.

[57] Brutin, D., Ajaev, V. S. and Tadrist, L., Pressure Drop and Void Fraction During Flow Boiling in Rectangular Minichannels in Weightlessness, Applied Thermal Engineering, vol. 51, no. 1-2, pp. 1317-1327, 2013.

[58] Kim, S. M., and Mudawar, I., Universal Approach to Predicting Two-Phase Frictional Pressure Drop for Mini/Micro-Channel Saturated Flow Boiling, International Journal of Heat and Mass Transfer, vol. 58, no. 1-2, pp. 718-734, 2013.

[59] Anwar, Z., Palm, B. and Khodabandeh, R. Flow Boiling Heat Transfer and Dryout Characteristics of R152a in a Vertical Mini-Channel, Experimental Thermal and Fluid Science, vol. 53 no. 14-15, pp. 207-217, 2014. [60] Charnay, R., Bonjour, J.,and Revellin, R., Experimental investigation of R-245fa flow boiling in minichannels at high saturation temperatures: Flow patterns and flow pattern maps, Int. J. Heat Fluid Flow, 46, no. 8, pp. 1-16. 2014.

[61] Choi, K., Oh, J., Saito, K., and Soo, J., Comparison of Heat Transfer Coefficient During Evaporation of Natural Refrigerants and R-1234yf in Horizontal Small Tube, International Journal of Refrigeration, vol. 41, pp. 210-218, 2013.

[62] Xu, Y., Fang, X., Li, G., and Li, D., An Experimental Investigation of Flow Boiling Heat Transfer and Pressure Drop of R134a in a Horizontal $2.168 \mathrm{~mm}$ Tube Under Hypergravity. Part I: Frictional Pressure Drop, International Journal of Heat and Mass Transfer, vol. 75, pp. 769-779, 2014.

[63] Piasecka, M., Correlations for Flow Boiling Heat Transfer in Minichannels With Various Orientations, International Journal of Heat and Mass Transfer, vol. 81, pp. 114-121, 2015.

[64] Xu, Y., Fang, X., Li, G., and Li, D., An Experimental Investigation of Flow Boiling Heat Transfer and Pressure Drop of R134a in a Horizontal 2.168 mm Tube Under Hypergravity. Part II: Frictional Pressure Drop, International Journal of Heat and Mass Transfer, vol. 80, pp. 597-604, 2015.

[65] Yen T.-H., Kasagi, N., and Suzuki, Y., Forced Convective Boiling Heat Transfer in Microtubes at Low Mass and Heat Fluxes, International Journal of Multiphase Flow, vol. 29, no. 12, pp. 1771-1792, 2003.

[66] Steinke, M. E., and Kandlikar, S. G., Control and Effect of Dissolved Air in Water During Flow Boiling in Microchannels, International Journal of Heat and Mass Transfer, vol. 47, pp. 1925-1935, 2004.

[67] Thome, J. R., Dupont, V., and Jacobi, A. M., Heat Transfer Model for Evaporation in Microchannels. Part I: Presentation of the Model, International Journal of Heat and Mass Transfer, vol. 47, no. 14-16, pp. 3375-3385, 2004.

[68] Yun, R., Kim, Y., and Kim, M. S., Convective Boiling Heat Transfer Characteristics of $\mathrm{CO}_{2}$ in Microchannels, International Journal of Heat and Mass Transfer, vol.48, no. 2, pp. 235-242, 2005.

[69] Li, Z., He, Y.-L., Tang, G.-H., and Tao, W.-Q., Experimental and Numerical Studies of Liquid Flow and Heat Transfer in Microtubes, International Journal of Heat and Mass Transfer, vol. 50, no. 17-18, pp. 3447-3460, 2007.

[70] Qi, S. L., Zhang, P., Wang, R. Z., and Xu, L. X., Flow Boiling of Liquid Nitrogen in Micro-Tubes: Part II - Heat Transfer Characteristics and Critical Heat Flux, International Journal of Heat and Mass Transfer, vol. 50, no. 25-26, pp. 5017-5030, 2007.

[71] Lee, P. C., and Pan, C., On the Eruptive Boiling in Silicon-Based Microchannels, International Journal of Heat and Mass Transfer, vol. 51, no. 19, pp. 4841-4849, 2008.

[72] In, S., and Jeong, S., Flow Boiling Heat Transfer Characteristics of R123 and R134a in a Micro-Channel, International Journal of Multiphase Flow, vol. 35, no. 11, pp. 987-1000, 2009.

[73] Roday, A. P., and Jensen, M. K., Study of The Critical Heat Flux Condition With Water and R-123 During Flow Boiling in Microtubes. Part I: Experimental Results and Discussion of Parametric Effects, International Journal of Heat and Mass Transfer, vol. 52, no. 13, pp. 3235-3249, 2009.

[74] Shiferaw, D., Karayiannis, T. G., and Kenning, D. B. R., Flow Boiling in a $1.1 \mathrm{~mm}$ Tube With R134a: Experimental Results and Comparison With Model, International Journal of Thermal Sciences, vol. 48, no. 2, pp. 331-341, 2009.

[75] Awad, M. M., and Muzychka, Y. S., Two-Phase Flow Modeling in Microchannels and Minichannels, Heat Transfer Engineering, vol. 31, pp. 1023-1033, 2010. 
[76] Celata, G. P., Saha, S. K., Zummo, G., and Dossevi, D., Heat Transfer Characteristics of Flow Boiling in a Single Horizontal Microchannel, International Journal of Thermal Sciences, vol. 49, no. 7, pp. 1086-1094, 2010.

[77] Kandlikar, S. G., Scale Effects on Flow Boiling Heat Transfer in Microchannels: A Fundamental Perspective, International Journal of Thermal Sciences, vol. 49, pp. 1073-1085, 2010.

[78] Ali, R. and Palm, B., Dryout Characteristics During Flow Boiling of R134a in Vertical Circular Minichannels, International Journal of Heat and Mass Transfer, vol. 54, no. 11, pp. 2434-2445, 2011.

[79] Choi, C., and Kim, M., Flow Pattern Based Correlations of Two-Phase Pressure Drop in Rectangular Microchannels, International Journal of Heat and Fluid Flow, vol. 32, no. 6, pp. 1199-1207, 2011.

[80] Costa-Patry, E., Olivier, J., Michel, B. and Thome, J. R. Two-Phase Flow of Refrigerants In $85 \mu \mathrm{m}-W i d e$ Multi-Microchannels: Part II - Heat Transfer With 35 Local Heaters, International Journal of Heat and Fluid Flow, vol. 32, no. 2, pp. 464-476, 2011.

[81] Ducoulombier, M., Colasson, S., Bonjour, J., and Haberschill, P., Carbon Dioxide Flow Boiling in a Single Microchannel - Part I: Pressure Drops, Experimental Thermal and Fluid Science, vol. 35, no. 4, pp. 581-596, 2011.

[82] Ducoulombier, M., Colasson, S., Bonjour, J., and Haberschill, P., Carbon Dioxide Flow Boiling in a Single Microchannel - Part II: Heat Transfer, Experimental Thermal and Fluid Science, vol. 35, no. 4, pp. 597-611, 2011.

[83] Wu, Z., Li, W., and Ye, S., Correlations for Saturated Critical Heat Flux in Microchannels, International Journal of Heat and Mass Transfer, vol. 54, no. 1-3, pp. 379-389, 2011.

[84] Liu, T. L., Fu, B. R., and Pan, C., Boiling Two-Phase Flow and Efficiency of Co- And Counter-Current Microchannel Heat Exchangers With Gas Heating, International Journal of Heat and Mass Transfer, vol. 55, no. 21-22, pp. 6130-6141, 2012.

[85] Vakili-Farahani, F., Agostini, B. and Thome, J. R., Experimental Study on Flow Boiling Heat Transfer of Multiport Tubes With R245fa and R1234ze(E), International Journal of Refrigeration, vol. 36, no. 2, pp. 335-352, 2013.

[86] Mahmoud, M. M. and Karayiannis, T. G., Heat Transfer Correlation for Flow Boiling in Small to Micro Tubes, International Journal of Heat and Mass Transfer, vol. 66, pp. 553-574, 2013.

[87] Kaya, A., Özdemir, M. R., and Koşar, A., High Mass Flux Flow Boiling and Critical Heat Flux in Microscale, International Journal of Thermal Sciences, vol. 65, pp. 70-78, 2013.

[88] Del Col, D., Bortolin, S., and Rossetto, L., Convective Boiling Inside a Single Circular Microchannel, International Journal of Heat and Mass Transfer, vol. 67, pp. 1231-1245, 2013.

[89] Liu, Y., Fletcher, D. F., and Haynes, B. S., On the Importance of Upstream Compressibility in Microchannel Boiling Heat Transfer, International Journal of Heat and Mass Transfer, vol. 58, no. 1-2, pp. 503$512,2013$.

[90] Kabova, Y., Kuznetsov, V. V., Kabov, O., Gambaryan-Roisman, T., and Stephan, P., Evaporation of a Thin Viscous Liquid Film Sheared by Gas in a Microchannel, International Journal of Heat and Mass Transfer, vol. 68, pp. 527-541, 2014.

[91] Rao, S. R., Houshmand, F., and Peles, Y., Transient Flow Boiling Heat-Transfer Measurements in Microdomains, International Journal of Heat and Mass Transfer, vol. 76, pp. 317-329, 2014.

[92] Mirmanto, M., Heat Transfer Coefficient Calculated Using Linear Pressure Gradient Assumption and Measurement For Flow Boiling in Microchannels, International Journal of Heat and Mass Transfer, vol. 79, pp. 269-278, 2014.

[93] Lim, T.-W., You, S.-S., Choi, J.-H., and Kim, H.-S., Experimental Investigation of Heat Transfer in TwoPhase Flow Boiling, Experimental Heat Transfer A Journal of Thermal Energy Generation, Transport, Storage, Conversion, vol. 28, no. 1, pp. 23-36, 2015.

[94] Peng, X. F., Liu, D., Lee, D. J., Yan, Y., and Wang, B. X., Cluster Dynamics and Fictitious Boiling in Microchannels, International Journal of Heat and Mass Transfer, vol. 43, no. 23, pp. 4259-4265, 2000.

[95] Lee, P. C., Tseng, F. G., and Pan, C., Bubble Dynamics in Microchannels. Part I: Single Microchannel, International Journal of Heat and Mass Transfer, vol. 47, no. 25, pp. 5575-5589, 2004.

[96] Li, H. Y., Tseng, F. G. and Pan, C., Bubble Dynamics in Microchannels. Part II: Two Parallel Microchannels, International Journal of Heat and Mass Transfer, vol. 47, no. 25, pp. 5591-5601, 2004. 
[97] Kenning, D. B. R., Wen, D. S., Das, K. S., and Wilson, S. K., Confined Growth of a Vapour Bubble in a Capillary Tube at Initially Uniform Superheat: Experiments and Modelling, International Journal of Heat and Mass Transfer, vol. 49, no. 23-24, pp. 4653-4671, 2006.

[98] Dong, T., Yang, Z., and Wu, H., Molecular Simulations of R141b Boiling Flow in Micro/Nano Channel: Interfacial Phenomena, Energy Conversion and Management, vol. 47, no. 15-16, pp. 2178-2191, 2006.

[99] Mukherjee, A., and Kandlikar, S.G., The Effect of Inlet Constriction on Bubble Growth During Flow Boiling in Microchannels, International Journal of Heat and Mass Transfer, vol. 52, pp. 5204-5212, 2009.

[100] Barber, J., Brutin, D., Sefiane, K., and Tadrist, L., Bubble Confinement in Flow Boiling of FC-72 in a "Rectangular" Microchannel of High Aspect Ratio, Experimental Thermal and Fluid Science, vol. 34, no.8, pp. 1375-1388, 2010.

[101] Fu, X., Zhang, P., Huang, C. J., and Wang, R. Z., Bubble Growth, Departure and the Following Flow Pattern Evolution During Flow Boiling in a Mini-Tube, International Journal of Heat and Mass Transfer, vol. 53, no. 21-22, pp. 4819-4831, 2010.

[102] Mukherjee, A., Kandlikar, S. G., and Edel, Z. J., Numerical Study of Bubble Growth and Wall Heat Transfer During Flow Boiling in a Microchannel, International Journal of Heat and Mass Transfer, vol. 54, pp. 3702-3718, 2011.

[103] Wang, Y., and Sefiane, K., Single Bubble Geometry Evolution in Micro-Scale Space, International Journal of Thermal Sciences, vol. 67, pp. 31-40, 2013.

[104] Pattamatta, A., Freystein, M., and Stephan, P., A Parametric Study on Phase Change Heat Transfer due to Taylor-Bubble Coalescence in a Square Minichannel, International Journal of Heat and Mass Transfer, vol. 76, pp. 16-32, 2014.

[105] Gong, S., and Cheng, P., Numerical Investigation of Saturated Flow Boiling in Microchannels by the Lattice Boltzmann Method, Numerical Heat Transfer, Part A: Applications, vol. 65, pp. 37-41, 2014.

[106] Satitchaicharoen, P., and Wongwises, S., Two-Phase Flow Pattern Maps for Vertical Upward Gas-Liquid Flow in Mini-Gap Channels, International Journal of Multiphase Flow, vol. 30, no.2, pp. 225-236, 2004.

[107] Owhaib, W., Palm, B., and Martín-Callizo, C., Flow Boiling Visualization in a Vertical Circular Minichannel at High Vapor Quality, Experimental Thermal and Fluid Science, vol. 30, no.8, pp. 755-763, 2006.

[108] Yen, T. H., Shoji, M., Takemura, F., Suzuki, Y., and Kasagi, N., Visualization of Convective Boiling Heat Transfer in Single Microchannels with Different Shaped Cross-Sections, International Journal of Heat and Mass Transfer, vol. 49, no. 21, pp. 3884-3894, 2006.

[109] Cheng, L., Ribatski, G., Wojtan, L., and Thome, J. R., New Flow Boiling Heat Transfer Model and Flow Pattern Map for Carbon Dioxide Evaporating Inside Horizontal Tubes, International Journal of Heat and Mass Transfer, vol. 49, no. 21, pp. 4082-4094, 2006.

[110] Pamitran, A. S., Choi, K. I., Oh, J. T., and Oh, H. K., Forced Convective Boiling Heat Transfer of R-410A in Horizontal Minichannels, International Journal of Refrigeration, vol. 30, no. 1, pp. 155-165, 2007.

[111] Saisorn, S., Kaew-On, J., and Wongwises, S., Flow Pattern and Heat Transfer Characteristics of R-134a Refrigerant During Flow Boiling in a Horizontal Circular Mini-Channel, International Journal of Heat and Mass Transfer, vol. 35, no. 19, pp. 887-895, 2011.

[112] Ozawa, M., Ami, T., Umekawa, H., Matsumoto, R., and Hara, T., Forced Flow Boiling of Carbon Dioxide in Horizontal Mini-Channel, International Journal of Thermal Sciences, vol. 50, no. 3, pp. 296-308, 2011.

[113] Dall'Olio, S., and Marengo, M., Boiling of R134a Inside a Glass Minichannel. A New Statistical Approach of Flow Pattern Characterization Based on Flow Visualization, International Journal of Heat and Mass Transfer, vol. 55, no. 4, pp. 1048-1065, 2012.

[114] Harirchian, T., and Garimella, S. V., Flow Regime-Based Modeling of Heat Transfer and Pressure Drop in Microchannel Flow Boiling, International Journal of Heat and Mass Transfer, vol. 55, no. 4, pp. 1246-1260, 2012.

[115] Costa-Patry, E., and Thome, J. R., Flow Pattern-Based Flow Boiling Heat Transfer Model for Microchannels, International Journal of Refrigeration, vol. 36, no. 2, pp. 414-420, 2013.

[116] Magnini, M., Pulvirenti, B., and Thome, J. R., Numerical Investigation of Hydrodynamics and Heat Transfer of Elongated Bubbles During Flow Boiling in a Microchannel, International Journal of Heat and Mass Transfer, vol. 59, no. 1, pp. 451-471, 2013. 
[117] Piasecka, M., Heat Transfer Mechanism, Pressure Drop and Flow Patterns During FC-72 Flow Boiling in Horizontal and Vertical Minichannels With Enhanced Walls, International Journal of Heat and Mass Transfer, vol. 66, pp. 472-488, 2013.

[118] Borhani, N., and Thome, J. R., Intermittent Dewetting and Dryout of Annular Flows, International Journal of Multiphase Flow, vol. 67, pp. 144-152, 2014.

[119] Charnay, R., Bonjour, J., and Revellin, R., Experimental Investigation of R-245fa Flow Boiling in Minichannels at High Saturation Temperatures: Flow Patterns and Flow Pattern Maps, International Journal of Heat Fluid Flow, vol. 46, pp. 1-16, 2014.

[120] C.B. Tibiriçá, C. B., and Ribatski, G., Flow Patterns and Bubble Departure Fundamental Characteristics During Flow Boiling in Microscale Channels, Experimental Thermal and Fluid Science, vol. 59, pp. 152-165, 2014.

[121] Brutin, D., Topin, F., and Tadrist, L., Experimental Study of Unsteady Convective Boiling in Heated Minichannels, International Journal of Heat and Mass Transfer, vol. 46, pp. 2957-2965, 2003.

[122] Bergles, A. E., and Kandlikar, S.G., On the Nature of Critical Heat Flux in Microchannels, Journal of Heat Transfer, vol. 127, no. 1, pp. 101-107, 2005.

[123] Kandlikar, S. G., Nucleation Characteristics and Stability Considerations During Flow Boiling in Microchannels, Experimental Thermal and Fluid Science, vol. 30, pp. 441-447, 2006.

[124] Kandlikar, S. G., Effect of Liquid-Vapor Phase Distribution on the Heat Transfer Mechanisms during Flow Boiling in Minichannels and Microchannels, Heat Transfer Engineering, vol. 27, no. 1, pp. 4-13, 2006.

[125] Qi, S. L., Zhang, P., Wang, R .Z., and Xu, L. X., Flow Boiling of Liquid Nitrogen in Micro-Tubes: Part I - The Onset of Nucleate Boiling, Two-Phase Flow Instability and Two-Phase Flow Pressure Drop, International Journal of Heat and Mass Transfer, vol. 50, pp. 4999-5016, 2007.

[126] Wang, G., Cheng, P., and Bergles, E., Effects of Inlet/Outlet Configurations on Flow Boiling Instability in Parallel Microchannels, International Journal of Heat and Mass Transfer, vol. 51, pp. 2267-2281, 2008.

[127] Lee, H. J., Liu, D. Y., and Yao, S., Flow Instability of Evaporative Micro-Channels International Journal of Heat and Mass Transfer, vol. 53, pp. 1740-1749, 2010.

[128] Lee, H. J., and Yao, S. C., System Instability of Evaporative Micro-Channels, International Journal of Heat and Mass Transfer, vol. 53, pp. 1731-1739, 2010.

[129] Tuo, H., and Hrnjak, P., Effect of Venting the Periodic Reverse Vapor Flow on the Performance of a Microchannel Evaporator in Air-Conditioning Systems, International Journal of Refrigeration, vol. 69, pp. 66-76, 2014.

[130] Tuo, H., and Hrnjak, P., Visualization and Measurement of Periodic Reverse Flow and Boiling Fluctuations in a Microchannel Evaporator of an Air-Conditioning System, International Journal of Heat and Mass Transfer, vol.71, pp. 639-652, 2014.

[131] Wang, Y., Sefiane, K., Wang, Z. G., and Harmand, S., Analysis of Two-Phase Pressure Drop Fluctuations During Micro-Channel Flow Boiling, International Journal of Heat and Mass Transfer, vol. 70, pp. 353-362, 2014.

[132] Edel, Z., and Mukherjee, A., Flow Boiling Dynamics of Water and Nanofluids in a Single Microchannel at Different Heat Fluxes, Journal of Heat Transfer, vol. 137, no.1, pp. 1-8, 2015.

[133] Koşar, A., Kuo, C. J., and Peles, Y., Boiling Heat Transfer in Rectangular Microchannels With Reentrant Cavities, International Journal of Heat and Mass Transfer, vol. 48, pp. 4867-4886, 2005.

[134] Sitar, A., Sedmak, I., and Golobic, I., Boiling of Water and FC-72 in Microchannels Enhanced With Novel Features, International Journal of Heat and Mass Transfer, vol. 55, pp. 6446-6457, 2012.

[135] Karayiannis, T. G., Mahmoud, M. M., Kenning, and D. B. R., A Study of Discrepancies in Flow Boiling Results in Small to Microdiameter Metallic Tubes, Experimental Thermal and Fluid Science, vol. 36, pp. 126142, 2012.

[136] Lee, W., Son, G., and Yoon, H. Y., Direct Numerical Simulation of Flow Boiling in a Finned Microchannel, International Communications in Heat and Mass Transfer, vol. 39, pp. 1460-1466, 2012.

[137] Zhou, S., Xu, X., and Sammakia, B. G., Modeling of Boiling Flow in Microchannels for Nucleation Characteristics and Performance Optimization, International Journal of Heat and Mass Transfer, vol. 64, pp. 706$718,2013$.

[138] Piasecka, M., The Use of Enhanced Surface in Flow Boiling Heat Transfer in a Rectangular Minichannel, Experimental Heat Transfer, vol. 27, pp. 231-255, 2014. 
[139] Pike-Wilson, E. A., and Karayiannis, T.G. Flow Boiling of R245fa in $1.1 \mathrm{~mm}$ Diameter Stainless Steel, Brass and Copper Tubes, Experimental Heat Transfer, vol. 59, pp. 166-183, 2014.

[140] Yang, F., Dai, X., Peles, Y., and Cheng, P., J. Khan, C. Li, Flow boiling phenomena in a single annular flow regime in microchannels (I): Characterization of flow boiling heat transfer, International Journal of Heat and Mass Transfer, vol. 68, pp. 703-715, 2014.

[141] Yang, F., Dai, X., Peles, Y., and Cheng, P., J. Khan, C. Li, Flow boiling phenomena in a single annular flow regime in microchannels (II): Reduced Pressure Drop and Enhanced Critical Heat Flux, , International Journal of Heat and Mass Transfer, vol. 68, pp. 716-724, 2014.

[142] Lee, W., and Son, G. Numerical Simulation of Bubble Growth and Heat Transfer During Flow Boiling in a Surface-Modified Microchannel, Heat Transfer Engineering, vol. 35, no. 5, pp. 501-507, 2014.

[143] Piasecka, M., Heat Transfer Research on Enhanced Heating Surfaces in Flow Boiling in a Minichannel and Pool Boiling, Annals of Nuclear Energy, vol. 73, pp. 282-293, 2014.

[144] Saisorn, S. and Wongwises S., Flow pattern, void fraction and pressure drop of two-phase air-water flow in a horizontal circular micro-channel. Experimental Thermal and Fluid Science, vol. 32, no. 3, pp. 748-760, 2008.

[145] Saisorn, S. and Wongwises, S., An inspection of viscosity model for homogeneous two-phase flow pressure drop prediction in a horizontal circular micro-channel, International Communications in Heat and Mass Transfer, vol. 35, no. 7, pp. 833-838, 2008.

[146] Saisorn, S. and Wongwises S., An experimental investigation of two-phase air-water flow through a horizontal circular micro-channel, Experimental Thermal and Fluid Science, vol. 33, no. 2, pp. 306-315, 2009.

[147] Saisorn, S. and Wongwises, S., The effects of channel diameter on flow pattern, void fraction and pressure drop of two-phase air-water flow in circular micro-channels, Experimental Thermal and Fluid Science, vol. 34, no. 4, pp. 454-462, 2010.

[148] Saisorn, S. and Wongwises, S., Two-phase air-water flow in micro-channels: An inspection of viscosity models for pressure drop prediction, International Communications in Heat and Mass Transfer, vol. 38, pp. 212$217,2011$.

[149] Saisorn, S., Kuaseng, P. and Wongwises, S. Heat transfer characteristics of gas-liquid flow in horizontal rectangular micro-channels, Experimental Thermal and Fluid Science, vol. 55, pp. 54-61, 2014.

[150] Suwankamnerd, P. and Wongwises, S. An Experimental Study of Two-phase Air-water Flow and Heat Transfer Characteristics of Segmented Flow in a Microchannel, Experimental Thermal and Fluid Science, vol. 62, pp. 29-39, 2015.

[151] Saisorn, S. and Wongwises, S., Adiabatic Two-Phase Gas-Liquid Flow Behaviors during Upward Flow in a Vertical Circular Micro-channel, Experimental Thermal and Fluid Science, vol. 69, pp. 158-168, 2015.

[152] Kaew-on, J. and Wongwises, S., Experimental investigation of evaporation heat transfer coefficient and pressure drop of R-410A in a multiport mini-channel, International Journal of Refrigeration, vol. 32, no. 1, pp. 124-137, 2009.

[153] Kaew-On, J., Sakamatapan, K. and Wongwises, S., Flow Boiling Heat Transfer of R-134a in a Multiport Minichannel Heat Exchangers, Experimental Thermal and Fluid Science, vol. 35 pp. 364-374, 2011.

[154] Kaew-On, J., Sakamatapan, K., Wongwises, S., Flow boiling pressure drop of R134a in the counter flow multiport minichannel heat exchangers, Experimental Thermal and Fluid Science, vol. 36, no. 1, pp. 107-117, 2012.

[155] Sakamatapan, K., Kaewon, J.,Dalkilic, A.S., Mahian, O. and Wongwises, S., Condensation heat transfer Characteristics of R-134a flowing inside the multiport minichannels, International Journal of Heat and Mass Transfer, vol. 64, pp. 976-985, 2013.

[156] Sakamatapan, K., Kaew-On, J. and Wongwises, S., Pressure drop during condensation of R134a flowing inside a multiport minichannel, International Journal of Heat and Mass Transfer, vol. 75, pp. 31-39, 2014.

[157] Nilpueng, K., and Wongwises, S., Experimental investigation of flow characteristics of HFC134a through short tube orifices, International Journal of Refrigeration, vol. 32, no. 5, pp. 854-864, 2009.

[158] Nilpueng, K. and Wongwises, S., Flow pattern, mass flow rate, pressure distribution, and temperature distribution of two-phase flow of HFC-134a inside short-tube orifices, International Journal of Refrigeration, vol. 32, no. 8, pp. 1864-1875, 2009.

[159] Nilpueng, K., and Wongwises, S., Flow mechanisms of HFC-410A inside short tube orifices during flashing process, International Journal of Heat and Mass Transfer vol. 53, no. 17-18, pp. 449-459, 2010. 
[160] Nilpueng, K. and Wongwises, S., Choked flow mechanism of HFC-134a flowing through short-tube orifices, Experimental Thermal and Fluids Science, vol. 35, pp. 347-354, 2011.

[161] Nilpueng, K. and Wongwises, S., Performance characteristics of HFC-134a and HFC-410A refrigeration system using a short-tube orifice as the expansion device, Heat and Mass Transfer, vol. 47, no. 10, pp. 1219-1227, 2011.

[162] Nilpueng, K. and Wongwises, S., Review on the Experimental Studies of Refrigerant Flow Mechanisms inside Short-Tube Orifices, International Journal of Refrigeration, vol. 35, no. 1, pp. 27-35, 2012.

[163] Nilpueng, K. and Wongwises, S., A review of numerical modelling studies on short-tube orifices performance with application to air-conditioning, International Journal of Refrigeration, vol. 35, no. 4, pp. 740749, 2012.

[164] Nilpueng, K. and Wongwises, S. Numerical simulation of refrigerants flowing through short-tube orifices during flashing process, HVAC\&R vol. 19, pp. 159-174, 2013.

[165] Saisorn, S., Kaew-on, J. and Wongwises, S., Flow pattern and heat transfer characteristics of R-134a refrigerant during flow boiling in a horizontal circular mini-channel, International Heat and Mass Transfer, vol. 53, no. 19-20, pp. 4023-4038, 2010.

[166] Saisorn, S., Kaew-On, J. and Wongwises, S., Two-phase flow of R-134a refrigerant during flow boiling through a horizontal circular mini-channel, Experimental Thermal and Fluid Science, vol. 35, pp. 887-895, 2011.

[167] Saisorn, S., Kaewon, J. and Wongwises, S., An Experimental Investigation of Flow Boiling Heat Transfer of R134a in horizontal and Vertical Mini-channels, Experimental Thermal and Fluid Science vol. 46, pp. 232-244, 2013.

[168] Keepaiboon, C. and Wongwises, S., Two-Phase flow patterns and heat transfer characteristics of R134a refrigerant during flow boiling in a single rectangular micro-channel, Experimental Thermal and Fluid Science vol. 66, pp. 36-45, 2015.

[169] Duangthongsuk, W., Dalkilic, A.S., and Wongwises, S., Convective heat transfer of Al2O3-water nanofluids in a microchannel heat sink, Current Nanoscience vol. 8, no. 3, pp. 317-322, 2012.

[170] Nitiapiruk, P., Mahian, O., Dalkilic, A.S. and Wongwises, S., Performance characteristics of a microchannel heat sink using $\mathrm{TiO}$ /water nanofluid and different thermophysical models, International Communications in Heat and Mass Transfer vol. 47, pp. 98-104, 2013.

[171] Saisorn, S, and Wongwises S., A review of two-phase gas-liquid adiabatic flow characteristics in microchannels. Renewable Sustainable Energy Reviews, vol. 32, no. 3, pp.748-760, 2008.

[172] Saisorn, S. and Wongwises, S., A critical review of recent investigations on heat transfer in flow boiling micro-channels, Frontier in Heat and Mass Transfer, vol. 3-013006, 2012.

[173] Saisorn, S., Wongwises, S., A critical review of recent investigations on two-phase pressure drop in flow boiling micro-channels, Frontier in Heat and Mass Transfer vol. 3, 013007, 2012.

[174] Awad, M. M., Dalkilic, A. S. and Wongwises, S., A critical review on condensation heat transfer in microchannels and minichannels, Journal of Nanotechnology in Engineering and Medicine, vol. 5, 010801-1, 2014.

[175] Awad, M. M., Dalkilic, A. S. and Wongwises, S., A Critical Review on Condensation Pressure Drop in Microchannels and Minichannels, in: Salim Newaz Kazi (Ed.), Heat Transfer Studies and Applications, InTech, Chapter 3, pp. 53-102, 2015. 


\section{APPENDIX}

Table A1. Mini/microchannel geometries and operating conditions

\begin{tabular}{|c|c|c|c|c|c|c|c|c|c|}
\hline Researcher & Fluid & $\begin{array}{c}\text { Hydraulic } \\
\text { Diameter } \\
(\mathrm{mm}) \\
\end{array}$ & $\begin{array}{l}\text { Channel } \\
\text { Geometry }\end{array}$ & $\begin{array}{c}\text { Port } \\
\text { Number }\end{array}$ & $\begin{array}{l}\text { Length } \\
(\mathrm{mm})\end{array}$ & $\begin{array}{l}\text { Pressure } \\
\text { (bar) }\end{array}$ & $\begin{array}{c}\text { Temperature } \\
\left({ }^{\circ} \mathrm{C}\right)\end{array}$ & $\begin{array}{r}\text { Mass Flux } \\
\left(\mathrm{kg} \mathrm{m}^{-2} \mathrm{~s}^{1}\right)\end{array}$ & $\begin{array}{l}\text { Channel Type } \\
\text { (Mini/Micro) }\end{array}$ \\
\hline Kew and Cornwell [10] & R141b & $1.39,1.69$ & - & - & 500 & - & - & - & - \\
\hline Lee and Lee [11] & $\mathrm{R} 113$ & - & Rectangular & 1 & 300 & - & - & $50-200$ & - \\
\hline Kandlikar and Steinke [12] & $\begin{array}{c}\text { R113, R124, } \\
\text { R134a, R141b, } \\
\text { R11, R22 } \\
\text { FC84, R123 }\end{array}$ & $\begin{array}{l}400 \mu \mathrm{m}- \\
2.97 \mathrm{~mm}\end{array}$ & $\begin{array}{c}\text { Round, } \\
\text { Rectangular, } \\
\text { Square }\end{array}$ & - & - & - & - & $50-1600$ & Mini \\
\hline $\begin{array}{l}\text { Kandlikar and } \\
\text { Balasubramanian [13] }\end{array}$ & FC77 & - & - & & - & - & - & - & Micro \\
\hline $\begin{array}{l}\text { Agostini and Bontemps } \\
\text { [14] }\end{array}$ & $\mathrm{R} 134 \mathrm{a}$ & 2.01 & Rectangular & 11 & 1100 & $\begin{array}{c}405-608 \\
\mathrm{kPa}\end{array}$ & $1-17$ & $90-295$ & Mini \\
\hline $\begin{array}{l}\text { Yun et al. } \\
{[15]}\end{array}$ & $\mathrm{CO}_{2}$ & $0.98,2.00$ & Circular & 2 & $\begin{array}{l}400, \\
1200\end{array}$ & - & $0.5-10$ & $500-3570$ & Mini \\
\hline Choi et al. [17] & $\mathrm{R} 22, \mathrm{R} 134 \mathrm{a}, \mathrm{CO}_{2}$ & $1-3$ & Circular & 1 & 2000 & - & 10 & $200-600$ & Mini \\
\hline Choi et al. [18] & R410A & $1.5-3$ & Circular & 1 & $\begin{array}{l}1500- \\
3000\end{array}$ & $\begin{array}{l}1.070- \\
1.329\end{array}$ & 10 & $300-600$ & Micro \\
\hline Pamitran et al. [19] & $\mathrm{CO}_{2}$ & $1.5-3$ & Circular & 1 & $\begin{array}{l}1500- \\
3000\end{array}$ & - & $-10,10$ & $200-600$ & Mini \\
\hline Bertsch et al. [20] & $\begin{array}{l}\text { Wetting and non- } \\
\text { wetting fluids }\end{array}$ & $0.16-2.92$ & $\begin{array}{c}\text { Circular- } \\
\text { Rectangular }\end{array}$ & 1 & 200 & $0.55-35$ & -291 & $20-3000$ & $\begin{array}{c}\text { Small } \\
\text { channel }\end{array}$ \\
\hline Choi et al. [21] & Propane & $1.5-3$ & Circular & 1 & $\begin{array}{l}1000- \\
2000\end{array}$ & $0-0.25$ & $0,5,10$ & $50-400$ & Mini \\
\hline Koşar [22] & $\begin{array}{l}\text { Water, R123, } \\
\text { R113, R134a, } \\
\text { R245fa }\end{array}$ & $0.223-3.1$ & $\begin{array}{l}\text { Circular and } \\
\text { rectangular }\end{array}$ & 1 & - & 1.8 .1988 & 30 & $50-1650$ & Mini, Micro \\
\hline Boudouh et al. [25] & $\begin{array}{c}\text { Copper-water } \\
\text { nanofluids }\end{array}$ & $800 \mu \mathrm{m}$ & Rectangular & 50 & - & - & - & - & Mini/micro \\
\hline Brix et al. [26] & $\mathrm{CO}_{2}$ & - & - & 11 & $0.47 \mathrm{~m}$ & - & - & - & Mini \\
\hline Dutkowski [27] & $\mathrm{R} 134 \mathrm{a}$ & 1.68 & Annular & - & 500 & & $5-15 \mathrm{~K}$ & $200-450$ & Mini \\
\hline Dutkowski [28] & $\begin{array}{l}\text { Air-water } \\
\text { mixture }\end{array}$ & $\begin{array}{l}1.05,1.35 \\
1.68,2.30\end{array}$ & Annular & - & - & - & - & $170-7350$ & Mini \\
\hline Pamitran et al. [29] & $\begin{array}{l}\text { R22, R134a, } \\
\text { R290, R744 }\end{array}$ & $0.5,1.5,3.0$ & Circular & - & $\begin{array}{l}330- \\
2000 \\
\end{array}$ & - & $0-15$ & $50-600$ & Small-tubes \\
\hline Ribeiro et al. [30] & R600a & - & - & - & - & - & $45-55$ & $\begin{array}{c}0.5-1.5 \mathrm{~kg} \\
\mathrm{~h}^{-1}\end{array}$ & Mini \\
\hline Bang et al. [31] & Water & 1.73 & - & - & - & $2-16$ & - & - & Mini \\
\hline Copetti et al. [33] & R134a & 2.6 & - & - & 158 & - & $12-22$ & $240-930$ & Mini-tube \\
\hline Kaew-On et al. [34] & R134a & $\begin{array}{c}1.1,1.2 \\
25.4\end{array}$ & Circular & 22 & - & $4-6$ & - & $300-800$ & Mini \\
\hline Wu et al. [35] & $\mathrm{CO}_{2}$ & 1.42 & Circular & 1 & 300 & - & -40 & $300-600$ & Mini \\
\hline $\begin{array}{l}\text { Kaew-On and Wongwises } \\
\text { [44] }\end{array}$ & R134a & 1.2 & Rectangular & 8 & - & 8 & - & $45-155$ & Mini \\
\hline Liu et al. [45] & $\begin{array}{c}\text { Kerosene kind } \\
\text { hydrocarbon fuel }\end{array}$ & 1 & Circular & 1 & 245 & 2.5 .2025 & $25-400$ & $1260-2160$ & Mini \\
\hline Maqbool et al. [46] & Propane & 1.224 & Circular & 1 & 245 & - & 33,43 & $100-400$ & Mini \\
\hline Mortada et al. [47] & R134a, R1234yf & 1.1 & Rectangular & 6 & 300 & 7.7 & - & $23-97$ & Mini \\
\hline Anwar [48] & $\mathrm{R} 134 \mathrm{a}$ & 1.6 & Circular & 1 & 245 & $\begin{array}{l}7.05- \\
8.15\end{array}$ & $27-32$ & $100-500$ & Mini \\
\hline Saisorn et al. [49] & R134a & 1.75 & Circular & 1 & 600 & $7-13$ & - & $200-1000$ & Mini \\
\hline Copetti et al. [50] & R600a & 2.6 & Circular & 1 & 185 & - & 22 & $240-440$ & Mini \\
\hline Maqbool et al. [51] & Propane & 1.7 & Circular & 1 & 245 & - & $23-43$ & $100-500$ & Mini \\
\hline \multirow{4}{*}{ Mikielewicz et al. [52] } & SES 36 & $\begin{array}{l}1.15- \\
2.3 \\
\end{array}$ & Circular & 1 & 380 & $1.1-1.9$ & $33-70$ & $300-900$ & Mini \\
\hline & R134a & - & - & - & - & $5.2-6.8$ & $17-27$ & $300-900$ & - \\
\hline & R123 & - & - & - & - & $1.1-2.4$ & $27-67$ & $300-900$ & - \\
\hline & Ethanol & - & - & - & - & $0.4-1$ & $51-75$ & $40-200$ & - \\
\hline
\end{tabular}


Table A1. Mini/microchannel geometries and operating conditions (cont.)

\begin{tabular}{|c|c|c|c|c|c|c|c|c|c|}
\hline Researcher & Fluid & $\begin{array}{c}\text { Hydraulic } \\
\text { Diameter } \\
(\mathrm{mm})\end{array}$ & $\begin{array}{l}\text { Channel } \\
\text { Geometry }\end{array}$ & $\begin{array}{c}\text { Port } \\
\text { Numb } \\
\text { er }\end{array}$ & $\begin{array}{l}\text { Length } \\
(\mathrm{mm})\end{array}$ & $\begin{array}{c}\text { Pressur } \\
\mathrm{e} \\
\text { (bar) }\end{array}$ & $\begin{array}{l}\text { Temperature } \\
\left({ }^{\circ} \mathrm{C}\right)\end{array}$ & $\begin{array}{l}\text { Mass Flux } \\
\left(\mathrm{kg} \mathrm{m}^{-2} \mathrm{~s}^{1}\right)\end{array}$ & $\begin{array}{l}\text { Channel Type } \\
\text { (Mini/Micro) }\end{array}$ \\
\hline Anwar et al. [59] & $\begin{array}{r}\text { R152a, } \\
\text { R134a } \\
\end{array}$ & 1.6 & Circular & 1 & 245 & - & 27,32 & $100-500$ & Mini \\
\hline Choi et al. [61] & $\begin{array}{c}\text { R744, R717, } \\
\text { R290, } \\
\text { R1234yf }\end{array}$ & $1.5,3$ & Circular & 1 & $\begin{array}{l}1000 \\
2000\end{array}$ & - & $0-15$ & $50-600$ & Mini \\
\hline $\mathrm{Xu}$ et al. [62] & $\mathrm{R} 134 \mathrm{a}$ & 2.168 & Circular & 1 & $0.2 \mathrm{~m}$ & $\begin{array}{c}0.071 \\
0.082\end{array}$ & $27.2,32.2$ & 725,910 & Mini \\
\hline Piasecka [63] & FC72 & 1.95 & Rectangular & 1 & 360 & 1.22 & - & $137-285$ & Mini \\
\hline $\mathrm{Xu}$ et al. [64] & $\mathrm{R} 134 \mathrm{a}$ & 2.168 & Circular & 1 & $0.2 \mathrm{~m}$ & $\begin{array}{r}0.071 \\
0.082 \\
\end{array}$ & $27.2,32.2$ & 725,910 & Mini \\
\hline Yen et al. [65] & $\begin{array}{l}\text { HCFC123 } \\
\text { FC72 } \\
\end{array}$ & $\begin{array}{c}0.19,0.3, \\
0.51\end{array}$ & Circular & 3 & 280 & $\begin{array}{c}110-145 \\
\mathrm{kPa}\end{array}$ & $10 \mathrm{~K}$ & $50-300$ & Micro \\
\hline Steinke and Kandlikar [66] & $\begin{array}{l}\text { Dissolved air } \\
\text { in water }\end{array}$ & $207 \mu \mathrm{m}$ & - & 6 & 57.15 & 1 & - & - & Micro \\
\hline $\begin{array}{l}\text { Yun et al. } \\
{[68]}\end{array}$ & $\mathrm{CO}_{2}$ & $1.08-1.54$ & Rectangular & 5 & - & - & $0.5-10$ & $200-400$ & Micro \\
\hline Qi et al. [70] & $\begin{array}{c}\text { Liquid } \\
\text { nitrogen }\end{array}$ & $0.531-1.931$ & Circular & 1 & 250 & $1.8-9.2$ & $78.2-79.8$ & $440-3000$ & Micro \\
\hline Lee and Pan [71] & Water & 0.0337 & Rectangular & 1 & 25 & 2.056 & - & $209-625$ & Micro \\
\hline In and Jeong [72] & R123-R134a & 0.19 & Circular & 1 & 31 & $1.58-11$ & $35.5,49.3$ & $314-470$ & Micro \\
\hline Roday and Jensen [73] & Water, R123 & $0.286-0.70$ & Circular & 1 & $\begin{array}{c}21.66- \\
58.91\end{array}$ & $\begin{array}{l}0.26- \\
2.25\end{array}$ & $2-80$ & $375-825$ & Micro \\
\hline Shiferaw et al. [74] & R134a & 1.1 & Circular & 1 & 150 & $6-12$ & - & $100-600$ & Micro \\
\hline Celata et el. [76] & FC72 & $\begin{array}{c}408 \mu \mathrm{m}-800 \\
\mu \mathrm{m}\end{array}$ & Circular & - & 102 & - & - & 1500 & Micro \\
\hline Ali and Palm [78] & R134a & $1.22-1.70$ & Circular & - & 220 & - & 27,32 & $50-600$ & Mini \\
\hline Choi and Kim [79] & $\begin{array}{l}\text { Water-liquid } \\
\text { Nitrogen-gas }\end{array}$ & $\begin{array}{c}141 \mu \mathrm{m}, 143 \\
\mu \mathrm{m} \\
304 \mu \mathrm{m}, 322 \\
\mu \mathrm{m}, 490 \mu \mathrm{m}\end{array}$ & Rectangular & - & 60 & - & - & - & Micro \\
\hline Costa-Party et al. [80] & $\begin{array}{l}\text { R236fa } \\
\text { R245fa }\end{array}$ & $85 \mu \mathrm{m}$ & - & 135 & $\begin{array}{c}2540 \\
\mu \mathrm{m}\end{array}$ & $\begin{array}{c}181- \\
326 \mathrm{kPa} \\
\end{array}$ & - & $500-1051$ & Multi-Micro \\
\hline Ducoulombier et al. [81] & $\mathrm{CO}_{2}$ & 0.529 & Annular & - & 60 & - & $-10,-5,0 \mathrm{C}$ & $200-1200$ & Micro \\
\hline Ducoulombier et al. [82] & $\mathrm{CO}_{2}$ & 0.529 & Annular & - & - & - & $-10,-5,0 \mathrm{C}$ & $200-1400$ & Micro \\
\hline Farahani et al. [85] & $\begin{array}{c}\text { R245fa } \\
\text { R1234ze (E) }\end{array}$ & 1.4 & Rectangular & 7 & 260 & - & $30-70$ & $50-400$ & Micro \\
\hline $\begin{array}{l}\text { Mahmoud and Karayiannis } \\
\text { [86] }\end{array}$ & R134a & $0.52-1.1$ & Circular & 1 & $\begin{array}{l}100- \\
450\end{array}$ & $6-10$ & - & $100-500$ & Micro \\
\hline Kaya et al. [87] & $\begin{array}{c}\text { De-ionized } \\
\text { water }\end{array}$ & $\begin{array}{c}0.249- \\
0.494 \\
\end{array}$ & Circular & 1 & $2-10$ & 1.0 & - & $\begin{array}{l}20,511- \\
38,111 \\
\end{array}$ & Mini \\
\hline Del Col et al. [88] & $\mathrm{R} 134 \mathrm{a}$ & 0.96 & Circular & 1 & 228 & 7.7 & 30 & $300-700$ & Mini \\
\hline Liu et al. [89] & $\begin{array}{c}\text { Water } \\
\text { n-hexane }\end{array}$ & $0.90-2$ & Circular & 1 & 270 & $1-2$ & $20-50$ & $60-180$ & Micro \\
\hline Rao et al. [91] & $\begin{array}{l}\text { Deionized } \\
\text { water }\end{array}$ & $230 \times 10^{-3}$ & Rectangular & 1 & 22 & 1 & 100 & 500 & Micro \\
\hline Mirmanto [92] & Water & $\begin{array}{c}0.438, \\
0.561,0.635\end{array}$ & Rectangular & 1 & 62 & 1.25 & 98 & 800 & Micro \\
\hline Lim et al. [93] & Water & $500 \times 10^{-3}$ & Rectangular & 1 & 60 & $1.1,1.7$ & - & $\begin{array}{l}200,400 \\
\quad 600\end{array}$ & Micro \\
\hline Lee et al. [95] & $\begin{array}{l}\text { De-ionized } \\
\text { water }\end{array}$ & $41.3 \mu \mathrm{m}$ & Trapezoidal & 1 & 28 & - & - & $170-477$ & Microchannel \\
\hline Li et al. [96] & $\begin{array}{c}\text { De-ionized } \\
\text { water }\end{array}$ & $47.7 \mu \mathrm{m}$ & Trapezoidal & 2 & 28 & - & - & $105-555$ & Micro \\
\hline Kenning et al. [97] & Water & $0.8-0.48$ & $\begin{array}{l}\text { Glass tube } \\
\text { circular }\end{array}$ & 1 & 150 & 1 & - & - & Micro \\
\hline $\begin{array}{l}\text { Mukherjee and Kandlikar } \\
\text { [99] }\end{array}$ & Water & - & Rectangular & 6 & 0.8 & 1 & $111.5,112.4$ & 120 & Micro \\
\hline Barber et al. [100] & FC72 & $727 \mu \mathrm{m}$ & Rectangular & - & 88 & - & - & - & Micro \\
\hline Fu et al. [101] & $\begin{array}{c}\text { Liquid } \\
\text { nitrogen }\end{array}$ & $1.3-1.5$ & 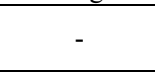 & - & 50 & - & - & - & Mini-tube \\
\hline
\end{tabular}


Table A1. Mini/microchannel geometries and operating conditions (cont.)

\begin{tabular}{|c|c|c|c|c|c|c|c|c|c|}
\hline Researcher & Fluid & $\begin{array}{c}\text { Hydraulic } \\
\text { Diameter }(\mathrm{mm})\end{array}$ & $\begin{array}{l}\text { Channel } \\
\text { Geometry }\end{array}$ & $\begin{array}{l}\text { Port } \\
\text { Nu. }\end{array}$ & $\begin{array}{l}\text { Length } \\
(\mathrm{mm})\end{array}$ & $\begin{array}{l}\text { Pressure } \\
\text { (bar) }\end{array}$ & $\begin{array}{l}\text { Temp. } \\
\left({ }^{\circ} \mathrm{C}\right)\end{array}$ & $\begin{array}{l}\text { Mass Flux } \\
\left(\mathrm{kg} \mathrm{m}^{-2} \mathrm{~s}^{1}\right)\end{array}$ & $\begin{array}{l}\text { Channel Type } \\
\text { (Mini/Micro) }\end{array}$ \\
\hline Mukherjee et al. [102] & Water & 0.229 & Square & 1 & 25.4 & 1 & 102 & $50-200(\mathrm{Re})$ & Micro \\
\hline Wang and Sefiane [103] & $\begin{array}{l}\text { FC72, n- } \\
\text { pentane }\end{array}$ & $\begin{array}{l}571 \times 10^{-3} \\
762 \times 10^{-3} \\
1454 \times 10^{-3}\end{array}$ & Rectangular & 1 & 80 & 1.013 & $56-35$ & $\begin{array}{l}11.2,22.4 \\
\quad 44.8\end{array}$ & Micro \\
\hline $\begin{array}{l}\text { Satitchaicharoen } \\
\text { Wongwises [106] }\end{array}$ & $\begin{array}{l}\text { Air, water, } \\
\text { glycerol, } \\
\text { solution }\end{array}$ & $\begin{array}{l}1.95,3.63,3.81 \\
3.87,5.58\end{array}$ & Rectangular & 5 & 1000 & - & - & - & Mini \\
\hline Owhaib et al. [107] & R134a & 1.33 & $\begin{array}{l}\text { Vertical tube- } \\
\text { circular }\end{array}$ & 1 & 235.5 & $\begin{array}{c}6.425- \\
8.64 \\
\end{array}$ & $24-34$ & 47.4-124.4 & Mini \\
\hline Yen et al. [108] & HCFC123 & $210-214$ & $\begin{array}{l}\text { Circular and } \\
\text { square tube }\end{array}$ & 1 & 100 & 1.63 & - & $100-800$ & Micro \\
\hline Cheng et al. [109] & $\mathrm{CO}_{2}$ & $0.8,10$ & Circular & - & - & $0.21-0.87$ & $\begin{array}{c}-28-25 \\
\mathrm{C} \\
\end{array}$ & $170-570$ & $\begin{array}{c}\text { Horizontal } \\
\text { tubes }\end{array}$ \\
\hline Pamitran et al. [110] & R410a & 1.5 .2003 & Circular & 1 & $\begin{array}{l}1500- \\
3000\end{array}$ & - & 10 & $300-600$ & Mini \\
\hline Saisorn et al. [111] & R134a & 1.75 & Circular & - & 600 & $\begin{array}{c}8,10 \\
13\end{array}$ & - & $200-1000$ & Mini \\
\hline Ozawa et al. [112] & $\mathrm{CO}_{2}$ & $0.51,1,2,3$ & Circular & 1 & $\begin{array}{c}400, \\
800, \\
1850, \\
1700\end{array}$ & $40-70$ & $\begin{array}{r}5.3- \\
28.7\end{array}$ & $80-900$ & Mini \\
\hline Dall'Olio and Marengo [113] & R134a & 4 & Circular & 1 & 320 & - & $20-25$ & $20-122$ & Mini \\
\hline Piasecka [117] & FC72 & 1.95 & Rectangular & 1 & 360 & 1 & $56-80$ & $140-300$ & Mini \\
\hline Borhani and Thome [118] & $\mathrm{R} 245 \mathrm{fa}$ & $3.36 \times 10^{-3}$ & Rectangular & 67 & 20 & - & - & 100,150 & Micro \\
\hline Charnay et al. [119] & R245fa & 3 & Circular & 1 & 185 & - & $60-120$ & $100-1500$ & Mini \\
\hline Tibiriçá and Ribatski [120] & $\begin{array}{l}\text { R134a, } \\
\text { R245fa }\end{array}$ & 0.4 & Circular & 1 & 200 & $\begin{array}{l}7.93 \\
1.84 \\
\end{array}$ & 31 & $100-900$ & Micro \\
\hline Brutin et al. [121] & n-pentane & $899 \mu \mathrm{m}$ & Rectangular & 1 & - & $\begin{array}{c}20-100 \\
\mathrm{kPa}\end{array}$ & - & - & Mini \\
\hline Kandlikar [123] & Water & 0.332 & Rectangular & 6 & - & $1.39-1.5$ & 111.5 & - & Micro \\
\hline Kandlikar [124] & Water & 0.332 & Rectangular & 6 & $\begin{array}{l}1.054 \mathrm{x} \\
0.197\end{array}$ & 1 & $\begin{array}{c}109.5, \\
110.9, \\
114 \\
\end{array}$ & $112-120$ & Micro \\
\hline Qi et al. [125] & $\begin{array}{c}\text { Liquid } \\
\text { nitrogen }\end{array}$ & $0.531-1.931$ & Circular & 1 & 250 & $\begin{array}{l}1.88- \\
8.112\end{array}$ & - & $440.6-2023.8$ & Micro \\
\hline Wang et al. [126] & Water & 0.186 & $\begin{array}{c}\text { Parallel } \\
\text { microchannel }\end{array}$ & 1 & 30 & - & 35 & $\begin{array}{c}91.4,124.03 \\
368.9 \\
\end{array}$ & Micro \\
\hline Lee et al. [127] & Water & $353 \mu \mathrm{m}$ & Rectangular & 48 & - & - & $5-30$ & $25-114$ & Micro \\
\hline Lee et al. [128] & Water & $235 \mu \mathrm{m}$ & Rectangular & 48 & - & - & 15 & 73 & Micro \\
\hline Tuo and Hrnjak [129] & R134a & 1 & Rectangular & 250 & 260 & - & - & $44-63$ & Mini \\
\hline Tuo and Hrnjak [130] & R134a & 1 & Rectangular & 250 & 190 & - & - & - & Mini \\
\hline Wang et al. [131] & FC72 & $\begin{array}{l}572 \times 10^{-3}, \\
762 \times 10^{-3}, \\
1454 \times 10^{-3}\end{array}$ & Rectangular & 1 & 80 & 1 & - & $\begin{array}{l}11.2,22.4 \\
\quad 44.8\end{array}$ & Micro \\
\hline Koşar et al. [133] & Water & $227 \mu \mathrm{m}$ & Rectangular & 5 & 100 & - & - & $41-302$ & Micro \\
\hline Sitar et al. [134] & FC72, Water & $25 \times 10^{-3}, 50 \times 10^{-}$ & Rectangular & $\begin{array}{l}64, \\
32 \\
\end{array}$ & $53 \mathrm{~mm}$ & 1.013 & 100 & $\begin{array}{r}8.7-247.9 \\
20.8-207.7 \\
\end{array}$ & Micro \\
\hline Karayiannis et al. [135] & $\mathrm{R} 134 \mathrm{a}$ & 1.1 & Circular & 1 & $\begin{array}{l}150- \\
450\end{array}$ & $6-10$ & - & $200-500$ & $\begin{array}{l}\text { Small to } \\
\text { micro } \\
\text { diameter }\end{array}$ \\
\hline Piasecka [138] & FC72 & 1.95 & Rectangular & 1 & 360 & $\begin{array}{l}1.35 \\
2.50 \\
1.25 \\
\end{array}$ & - & 235,285 , & Mini \\
\hline $\begin{array}{l}\text { Pike-Wilson and Karayiannis } \\
\text { [139] }\end{array}$ & $\mathrm{R} 245 \mathrm{fa}$ & 1.1 & Circular & 1 & 300 & $1.8,2.4$ & - & $100-400$ & Mini \\
\hline Yang et al. [140] & $\begin{array}{c}\text { Deionized } \\
\text { water }\end{array}$ & $\begin{array}{l}222 \times 10^{-3} \\
308 \times 10^{-3}\end{array}$ & Rectangular & 5 & 10 & - & - & $160-404$ & Micro \\
\hline Piasecka [143] & FC72 & 1.95 & Rectangular & 1 & 360 & 1 & - & $212-285$ & Mini \\
\hline
\end{tabular}


Journal of Thermal Engineering, Review Article, Vol. 4, No. 3, pp. 2037-2074, April, 2018

Table A2. Selected heat transfer models according to different researchers

\begin{tabular}{|c|c|}
\hline Researcher & Proposed model \\
\hline Yun et al. [15] & $h=16.26 q^{0.72} p_{r}^{0.88}$ \\
\hline Jokar et al. [16] & $N u_{t p}=0.603 \mathrm{Re}_{1}^{0.5} \operatorname{Pr}_{1}^{0.5} x^{-2}\left(\frac{G^{2}}{\rho_{1}^{2} C_{p, 1} \Delta T}\right)^{-0.1}\left(\frac{\rho_{1}^{2} i_{f g}^{\prime}}{G^{2}}\right)^{-0.5}\left(\frac{\rho_{1} \sigma}{\mu_{1} G}\right)^{1.1}\left(\frac{\rho_{1}}{\rho_{1}-\rho_{V}}\right)^{2}$ \\
\hline Bertsch et al. [20] & $\begin{array}{l}h_{F B}=h_{N B} S+h_{\text {conv }, t p} F, h_{N B}=55 P_{r}^{0.12-0.2 \log _{10} R_{p}}\left(-\log _{10} P_{r}\right)^{-0.55} M^{-0.55}\left(q^{\prime \prime}\right)^{0.67} \\
h_{\text {con }, t p}=h_{\text {con }, 1}(1-x)+h_{\text {conv }, v} x \\
h_{\text {conv }, 1}=\left(\begin{array}{c}0.0668 \frac{D_{h}}{L} \operatorname{Re} \operatorname{Pr} \\
1+0.04\left[\frac{D_{h}}{L} \operatorname{Re} \operatorname{Pr}\right]^{2 / 3}\end{array}\right) \frac{k_{1}}{D_{h}} \\
\operatorname{Re}_{1}=\frac{G D_{h}}{\mu_{1}}, \operatorname{Re}_{v}=\frac{G D_{h}}{\mu_{v}} S=f(x)=1-x \\
F=1+f(C o, x)=1+a e^{-b C o}\left(x^{2}-x^{6}\right) \\
h_{F B}=h_{N B}(1-x)+h_{\text {conv }, t p}\left[1+a\left(x^{2}-x^{6}\right) e^{-b C o}\right] h_{F B}=h_{N B}(1-x)+h_{\text {conv }, t p}\left[1+80\left(x^{2}-x^{6}\right) e^{-0.6 C o}\right]\end{array}$ \\
\hline Sun and Mishima [24] & $h_{t p}=\frac{6 \operatorname{Re}_{l o}^{1.05} B o^{0.54}}{W e_{l}^{0.191}\left(\rho_{l} / \rho_{g}\right)^{0.142}} \frac{\lambda_{l}}{d_{h}}$ and $W e_{l}=\frac{G^{2} D_{h}}{\sigma \rho_{l}}$ \\
\hline Bang et al. [31] & $N u_{x}=4.364+8.68 \times\left(1000 \times x^{*}\right)^{-0.506} \times e^{-41 x^{*}}$ \\
\hline Kaew-On et al. [34] & $h_{T P}=S B o^{0.185} W_{l}^{0.0013} h_{l} ; B o=\frac{q^{\prime \prime}}{G i_{l v}} ; W e_{l}=\frac{G^{2} d_{h}}{\rho_{l} \sigma}$ \\
\hline Oh et al. [37] & 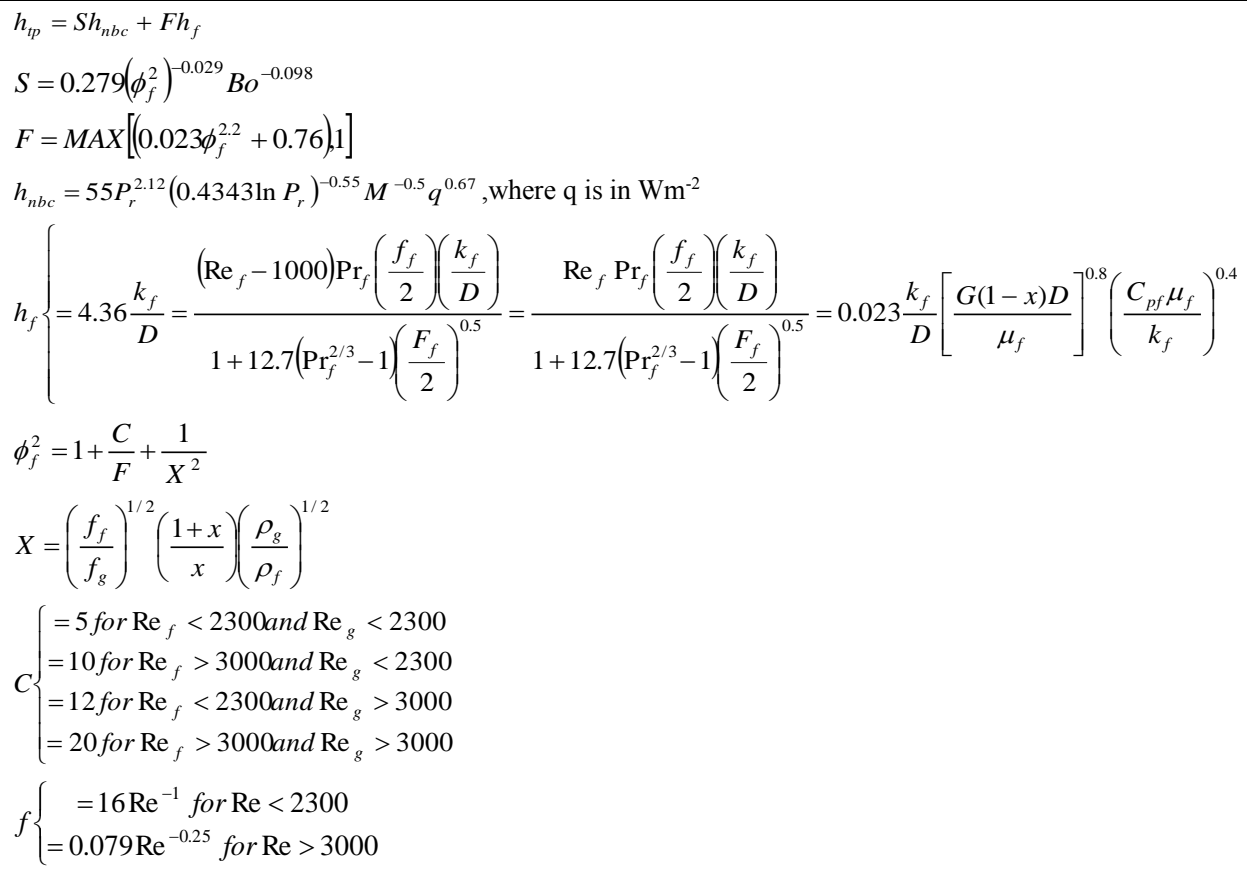 \\
\hline $\begin{array}{l}\text { Kaew-On } \\
\text { Wongwises [44] }\end{array}$ & $\begin{array}{l}h_{t p}=S B o^{1.032} W_{l}^{0.052} \mathrm{Co}^{-0.391} h_{l} \\
S=1.737+0.97\left(\beta \phi_{l}^{2}\right)^{0.523} ; \phi_{l}^{2}=1+\frac{C}{X}+\frac{1}{X^{2}} \\
\text { for } 45 \leq G \leq 77 \mathrm{~kg} / \mathrm{m}^{2} s, C=23.23 e^{-0.0027 \beta \mathrm{Re}_{l}} ; \text { for } 77 \leq G \leq 155 \mathrm{~kg} / \mathrm{m}^{2} s, C=44.28 e^{-0.0032 \beta \mathrm{Re}_{l}} \\
B o=\frac{q^{\prime \prime}}{G i_{l v}} ; W e_{l}=\frac{G^{2} d_{h}}{\rho_{l} \sigma} ; C o=\left(\frac{(1-x)}{x}\right)^{0.8}\left(\frac{\rho_{v}}{\rho_{l}}\right)^{0.5}\end{array}$ \\
\hline
\end{tabular}


Journal of Thermal Engineering, Review Article, Vol. 4, No. 3, pp. 2037-2074, April, 2018

Table A2. Selected heat transfer models according to different researchers (cont.)

\begin{tabular}{|c|c|}
\hline Researcher & Proposed model \\
\hline Liu et al. [45] & $\begin{array}{l}h=235.7 \Delta T_{\text {sub }}^{-0.836} 0.25 M P a<P<2.5 M P a, 50^{\circ} C<\Delta T_{\text {sub }}<370^{\circ} \\
h=0.33 \Delta T_{\text {sub }}^{-0.836}(q+37.3)\end{array}$ \\
\hline Mortada et al. [47] & $\begin{array}{l}N u=a\left(B o^{2} W e_{L}\right) \operatorname{Coc}^{c} \operatorname{Re}_{l O}^{d} \\
\operatorname{Re}_{l O}^{d}=\frac{G d_{h}}{\mu_{l}} \\
C o c=\left[\frac{(1-x)}{x}\right]^{0.7}\left(\frac{\rho_{v}}{\rho_{l}}\right)^{0.5} \\
\text { Coefficients of a, b, c and d can be seen in the original paper according to mass and heat fluxes. }\end{array}$ \\
\hline Kim and Mudavar [56] & $\begin{array}{l}h_{t p}=\left(h_{n b}^{2}+h_{c b}^{2}\right)^{0.5} \\
h_{n b}=\left[2345\left(B o \frac{P_{H}}{P_{F}}\right)^{0.7} P_{R}^{0.38}(1-x)^{-0.51}\right]\left(0.023 \operatorname{Re}_{f}^{0.8} \operatorname{Pr}_{f}^{0.4} \frac{k_{f}}{D_{h}}\right) \\
h_{c b}=\left[5.2\left(B o \frac{P_{H}}{P_{F}}\right)^{0.08} W e_{f o}^{-0.54}+3.5\left(\frac{1}{X_{t t}}\right)^{0.94}\left(\frac{\rho_{g}}{\rho_{f}}\right)^{0.25}\right]\left(0.023 \operatorname{Re}_{f}^{0.8} \operatorname{Pr}_{f}^{0.4} \frac{k_{f}}{D_{h}}\right) \\
B o=\frac{q_{H}^{\prime \prime}}{G h_{f g}}, P_{R}=\frac{P}{P_{c r i t}}, \operatorname{Re}_{f}=\frac{G(1-x) D_{h}}{\mu_{f}}, W e_{f o}=\frac{G^{2} D_{h}}{\rho_{f} \sigma}, X_{t t}=\left(\frac{\mu_{f}}{\mu_{g}}\right)^{0.1}\left(\frac{1-x}{x}\right)^{0.9}\left(\frac{\rho_{g}}{\rho_{f}}\right)^{0.5}\end{array}$ \\
\hline Qi et al. [70] & $\begin{array}{l}B o=\frac{q}{G h_{f g}} ; X=\left(\frac{1-x}{x}\right)^{0.9}\left(\frac{\rho_{G}}{\rho_{L}}\right)^{0.5}\left(\frac{\mu_{L}}{\mu_{G}}\right)^{0.1} \\
K_{p}=p /\left[\sigma g\left(\rho_{L}-\rho_{G}\right)^{-1 / 2}\right\rfloor \\
N u_{T p}=1059.83 B o^{0.454} W e^{0.045} K_{p}^{0.106} X^{0.107} \mathrm{Co}^{-1.825} ; x<0.3 \\
N u_{T p}=0.0042 B o^{-0.872} W e^{-0.059} K_{p}^{0.293} X^{0.065} \mathrm{Co}^{-1.704} ; x \geq 0.3 \\
N u_{T p}=h_{T P} D / k_{L}\end{array}$ \\
\hline $\begin{array}{l}\text { Mahmoud } \\
\text { Karayiannis [86] }\end{array}$ & $\begin{array}{l}h_{t w}=S_{\text {new }} h_{\text {cooper }}+F_{\text {new }} h_{L} ; h_{\text {cooper }}=55 P_{r}^{0.12-0.434 \ln R_{p}}\left(-\log P_{r}\right)^{-0.55} M^{-0.55} q^{0.67} \\
h_{L}=\left\{\begin{array}{l}4.36 \frac{k_{L}}{D}, \operatorname{Re}_{L}\langle 2000 \\
0.023 \operatorname{Re}_{L}^{0.8} \operatorname{Pr}_{L}^{0.4} \frac{k_{L}}{D}, \operatorname{Re}_{L}>3000\end{array}\right. \\
\operatorname{Re}_{L}=\frac{(1-x) G D}{\mu_{L}} \\
F_{\text {new }}=\left(1+\frac{A}{X}\right)^{0.64} ; A=2.812 C o^{-0.408} \\
X=\left(\frac{f_{L}}{f_{g}}\right)^{0.5}\left(\frac{\rho_{g}}{\rho_{L}}\right)^{0.5}\left(\frac{1-x}{x}\right) \\
S_{\text {new }}=\frac{1}{1+2.56 \times 10^{-6}\left(\operatorname{Re}_{L} F_{\text {new }}^{1.25}\right)^{1.17}}\end{array}$ \\
\hline Cheng et al. [109] & $\begin{array}{l}\text { Nucleate boiling heat transfer correlation } \\
h_{n b}=131 p_{r}^{-0.0063}\left(-\log _{10} p_{r}\right)^{-0.55} M^{-0.5} q^{0.58} \\
\text { The following boiling suppression factor correlation } \\
\text { If } x<x_{\mathrm{IA}} \quad ; \quad S=1 \\
\text { If } x \geq x_{\mathrm{IA}} \quad ; \quad S=1-1.14\left(D / D_{\text {ref }}\right)^{2}\left(1-\delta / \delta_{\mathrm{IA}}\right)^{2.2} \\
\text { Dry out inception vapor quality correlation } \\
x_{d i}=0.58 \exp \left(\left[0.52-0.67 W e_{v}^{0.17} \mathrm{Fr}_{v}^{0.348}\left(\rho_{v} / \rho_{L}\right)^{0.25}\left(q / q_{\text {crit }}\right)^{0.7}\right]\right)\end{array}$ \\
\hline
\end{tabular}

Table A3. Selected CHF models according to different researchers 
Journal of Thermal Engineering, Review Article, Vol. 4, No. 3, pp. 2037-2074, April, 2018

\begin{tabular}{|c|c|}
\hline Researcher & Proposed model \\
\hline Ong and Thome [38] & $\begin{array}{l}\quad \frac{q_{c h f}}{G h_{l v}}=0.12\left(\frac{\mu_{L}}{\mu_{V}}\right)^{0.183}\left(\frac{\rho_{L}}{\rho_{V}}\right)^{0.062} W e_{L}^{-0.141}\left(\frac{L_{e v}}{D}\right)^{-0.7}\left(\frac{D}{D_{t h}}\right)^{0.11} \\
\text { where } \mathrm{Co}=0.5 \\
D_{t h}=\frac{1}{C o} \sqrt{\frac{\sigma}{g\left(\rho_{L}-\rho_{V}\right)}}, W e_{L}=\frac{G^{2} L_{e v}}{\rho_{L} \sigma} \\
\text { For } \mathrm{D}=0.35-3.04 \mathrm{~mm}, \quad \mathrm{G}=84-3736 \quad \mathrm{~kg} / \mathrm{m} 2 \mathrm{~s}, \quad \mathrm{We}_{\mathrm{L}}=7-201232, \quad \mu_{\mathrm{L}} / \mu_{\mathrm{V}}=14.4-53.1, \\
\rho_{\mathrm{L}} / \rho_{\mathrm{V}}=0.024-0.036, \mathrm{~L}_{\mathrm{ev}} \mathrm{D}=22.7-178\end{array}$ \\
\hline Wu and $\mathrm{Li}[41]$ & $\begin{aligned} B l_{c h f} & =\frac{q_{c h f}}{G h_{l v}}=0.62\left(\frac{L_{h}}{d_{h e}}\right)^{-1.19} x_{e}^{0.82} \text { for } \frac{L_{h}}{d_{h e}} \leq 150, B o \mathrm{Re}_{l}^{0.5} \leq 200 \\
B l_{c h f} & =1.16 \times 10^{-3}\left(W e_{m} C a_{l}^{0.8}\right)^{-0.16} \text { for } \frac{L_{h}}{d_{h e}}>150, B o \mathrm{Re}_{l}^{0.5} \leq 200 \\
W e_{m} & =\frac{G^{2} d_{h e}}{\rho_{m} \sigma}, C a_{l}=\frac{\mu_{l} G}{\rho_{l} \sigma}\end{aligned}$ \\
\hline Mikilelewicz et al. [52] & $\frac{q_{c r}}{h_{l v} G}=0.62\left(\frac{\rho_{v}}{\rho_{l}}\right)^{-0.02}\left(W e_{D}\right)^{-0.05}\left(\frac{L}{D}\right)^{-1.17}$ \\
\hline Wu et al. [83] & $B l_{c h f}=\frac{q_{c h f}}{G h_{l v}}=0.60\left(\frac{L_{h}}{d_{h e}}\right)^{-1.19} x_{e}^{0.817}$ \\
\hline Kaya et al. [87] & $q_{C H F}^{\prime \prime}=0.8636 .10^{-4} \frac{\mu_{L} h_{F G}}{d_{i}^{1.32}} \operatorname{Re}^{1.06}\left(\frac{L_{h}}{d_{i}}\right)^{-0.72}\left(\frac{c_{p, e} \Delta T_{\text {sub,i }}}{h_{F g, e}}\right)^{0.2}$ \\
\hline Koşar et al. [133] & $q_{C H F}^{\prime \prime}=0.0035 G h_{F G} W e^{-0.12}$ \\
\hline
\end{tabular}

